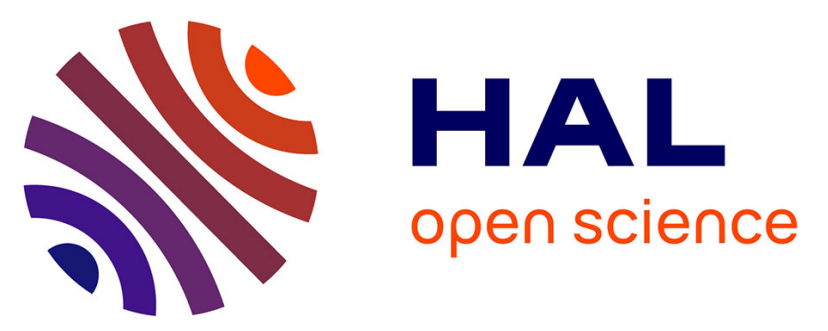

\title{
Modeling the effect of soil meso- and macropores topology on the biodegradation of a soluble carbon substrate
}

\author{
Laure E. Vogel, David D. Makowski, Patricia P. Garnier, Laure
}

Vieublé-Gonod, Yves Coquet, Xavier Raynaud, Naoise Nunan, Claire Chenu, Ruth Falconer, Valérie Pot

\section{To cite this version:}

Laure E. Vogel, David D. Makowski, Patricia P. Garnier, Laure Vieublé-Gonod, Yves Coquet, et al.. Modeling the effect of soil meso- and macropores topology on the biodegradation of a soluble carbon substrate. Advances in Water Resources, 2015, 83, pp.123-136. 10.1016/j.advwatres.2015.05.020 . insu-01170155

\section{HAL Id: insu-01170155 \\ https://hal-insu.archives-ouvertes.fr/insu-01170155}

Submitted on 8 Jun 2020

HAL is a multi-disciplinary open access archive for the deposit and dissemination of scientific research documents, whether they are published or not. The documents may come from teaching and research institutions in France or abroad, or from public or private research centers.
L'archive ouverte pluridisciplinaire HAL, est destinée au dépôt et à la diffusion de documents scientifiques de niveau recherche, publiés ou non, émanant des établissements d'enseignement et de recherche français ou étrangers, des laboratoires publics ou privés. 


\section{Accepted Manuscript}

Modeling the effect of soil meso- and macropores topology on the biodegradation of a soluble carbon substrate

Laure E. Vogel, David Makowski, Patricia Garnier, Laure Vieublé-Gonod, Yves Coquet, Xavier Raynaud, Naoise Nunan, Claire Chenu, Ruth Falconer, Valérie Pot

PII: S0309-1708(15)00114-1

DOI: 10.1016/j.advwatres.2015.05.020

Reference: $\quad$ ADWR 2392

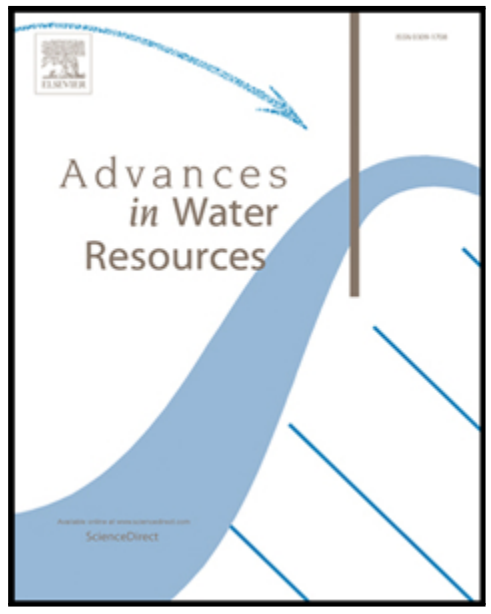

To appear in: $\quad$ Advances in Water Resources

Received date: $\quad 16$ July 2014

Revised date: $\quad 2$ April 2015

Accepted date: 24 May 2015

Please cite this article as: Laure E. Vogel, David Makowski, Patricia Garnier, Laure Vieublé-Gonod, Yves Coquet, Xavier Raynaud, Naoise Nunan, Claire Chenu, Ruth Falconer, Valérie Pot, Modeling the effect of soil meso- and macropores topology on the biodegradation of a soluble carbon substrate, Advances in Water Resources (2015), doi: 10.1016/j.advwatres.2015.05.020

This is a PDF file of an unedited manuscript that has been accepted for publication. As a service to our customers we are providing this early version of the manuscript. The manuscript will undergo copyediting, typesetting, and review of the resulting proof before it is published in its final form. Please note that during the production process errors may be discovered which could affect the content, and all legal disclaimers that apply to the journal pertain.

(C) 2015, Elsevier

Licensed under the Creative Commons Attribution-NonCommercial-NoDerivatives 4.0 International http://creativecommons.org/licenses/by-nc-nd/4.0/

\section{(cc) EY-NC-ND}

The published article is available from doi: http://dx.doi.org/10.1016/j.advwatres.2015.05.020 


\section{Highlights}

- We modeled macropore topology control on soluble C substrate degradation by bacteria

- A 3D Lattice-Boltzmann model was coupled to a compartmental model for biodegradation

- Macropores, water and bacteria distributions were described at submillimeter scale

- Physical and biological effects were quantified on a complete factorial design

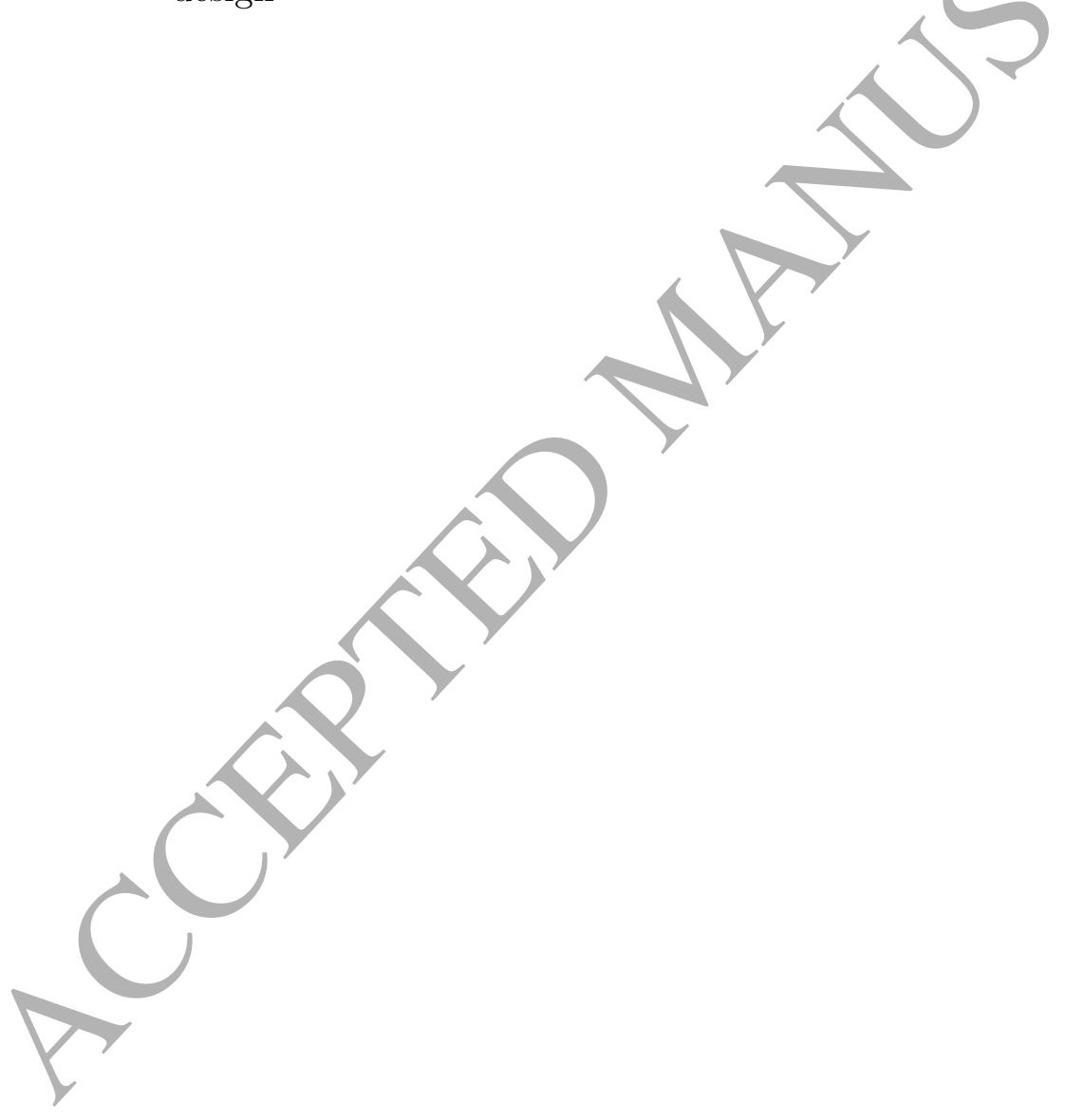




\section{Modeling the effect of soil meso- and macropores topology on the biodegradation of a soluble carbon substrate.}

Laure E. Vogel ${ }^{\mathrm{a}, *}$, David Makowski ${ }^{\mathrm{b}}$, Patricia Garnier ${ }^{\mathrm{a}}$, Laure Vieublé-Gonod $^{\mathrm{a}}$, Yves Coquet $^{\mathrm{c}, \mathrm{d}, \mathrm{e}}$, Xavier Raynaud $^{\mathrm{f}}$, Naoise Nunan ${ }^{\mathrm{g}}$, Claire Chenu $^{\text {h}}$, Ruth Falconer ${ }^{\mathrm{i}}$, Valérie Pot ${ }^{\mathrm{a}}$,

${ }^{a}$ INRA, AgroParisTech, UMR 1091 Environnement et Grandes Cultures, F-78850 Thiverval-Grignon, France

${ }^{b}$ INRA, AgroParisTech, UMR 211 Agronomie, F-78850 Thiverval-Grignon, France ${ }^{c}$ Université Orléans, ISTO, UMR 7327, 45071 Orléans, France ${ }^{d}$ CNRS/INSU, ISTO, UMR 7327, 45071 Orléans, France ${ }^{e}$ BRGM, ISTO, UMR 7327, BP 36009, 45060 Orléans, France

${ }^{f}$ Sorbonne Universités, UPMC Univ Paris 06, Institute of Ecology and Environmental Sciences - Paris, Paris, France

${ }^{g}$ CNRS, Institute of Ecology and Environmental Sciences - Paris, Campus AgroParisTech, Thiverval-Grignon, France

${ }^{h}$ AgroParisTech, Institute of Ecology and Environmental Sciences - Paris, Campus AgroParisTech, Thiverval-Grignon, France

${ }^{i}$ SIMBIOS Centre, Bell Street, Dundee, University of Abertay, Dundee, Scotland, DD1

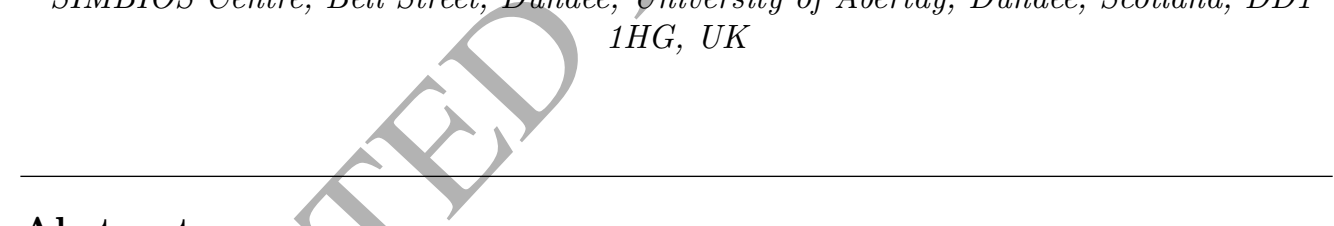

\section{Abstract}

Soil structure and interactions between biotic and abiotic processes are increasingly recognized as important for explaining the large uncertainties in the outputs of macroscopic SOM decomposition models. We present a numerical analysis to assess the role of meso- and macropore topology on the biodegradation of a soluble carbon substrate in variably water saturated and pure diffusion conditions. Our analysis was built as a complete factorial

${ }^{*}$ Corresponding author $(+33130815922)$

**Principal corresponding author $(+33130815402)$

Email addresses: laure.vogel@grignon.inra.fr (Laure E. Vogel), valerie.pot@grignon.inra.fr (Valérie Pot) 
design and used a new 3D pore-scale model, LBioS, that couples a diffusion Lattice-Boltzmann model and a compartmental biodegradation model. The scenarios combined contrasted modalities of four factors: meso- and macropore space geometry, water saturation, bacterial distribution and physiology. A global sensitivity analysis of these factors highlighted the role of physical factors in the biodegradation kinetics of our scenarios. Bacteria location explained $28 \%$ of the total variance in substrate concentration in all scenarios, while the interactions among location, saturation and geometry explained up to $51 \%$ of it.

Keywords: Biodegradation, Lattice-Boltzmann method, Pore-scale heterogeneity, Spatial distribution, Substrate diffusion, Microbial habitats

\section{Introduction}

Soil is the most complex and heterogeneous material on earth due to its complicated architecture and the high diversity of organisms that it hosts. It is also one of the biggest carbon storage pools containing more than twice the amount of carbon present in the atmosphere. Soil Organic Matter (SOM) decomposition, even if it is evaluated to a relative loss of carbon of less than a percent [1], is thus a key process regarding $\mathrm{CO}_{2}$ emissions.

Experimental observations at the millimeter scale have shown that the distribution of bacteria is characterized by the presence of hot-spots [2-5]. The heterogeneity of the arrangement of soil particles (inter-aggregate vs intra-aggregate porosity) and the variation of water saturation conditions contribute to maintain gradients in abiotic conditions (nutrients, $\mathrm{pH}$ and redox conditions) and therefore locally promote or not the growth of microorganisms [6]. The patchy distribution patterns of bacteria in soils can result in spatial disconnection between organic residues and decomposers and thereby influence the kinetics of decomposition of organic compounds, as has been shown experimentally by $[7,8]$. The sinuous water diffusion pathways in the soil pore space through which nutrients can be transported can thus play a major role in these situations $[9,10]$ although this can be mitigated by cells migration mechanisms allowing the microorganisms to reach distant resources [11-14].

The complex interactions between the biotic and abiotic components of soil that occur at the scale of the microhabitats of soil decomposers has been identified as being a major regulator of the $\mathrm{C}$ and $\mathrm{N}$ cycles [15-17]. 
Despite these considerations, SOM decomposition models are dominated by macroscopic models in which soil structure is not explicitely represented and the role of physical environmental conditions - especially hydration statuses - is described by non-robust empirical macroscopic functions $[18,19]$. Indeed, since microscale heterogeneities are hidden within these macroscale functions, they may appear to cause large uncertainties in model outputs $[20,21]$

The combination of non invasive X-ray tomographic tools to describe the $3 \mathrm{D}$ structure of soil $[22,23]$ and the development of pore-scale models [24] can now be used to test hypotheses on the role of soil structure. An increasing number of modeling studies have begun to account for pore-scale spatial heterogeneity when simulating biodegradation kinetics (e.g. [25-30]) but they have been restricted to relatively simple artificial media. Few attempts to model biological activity using 3D tomographic images of soil have pointed out that the combination of different soil pore space geometries and hydration status can affect organic matter decomposition [31] and/or the growth and colonization of soil by fungi [32]. However, a global sensitivity analysis to assess the influence of pore space topology, hydration status, spatial arrangement of organic substrates and decomposers, and the intrinsic physiology of the microorganisms on the decomposition of SOM has yet to be tackled.

The aim of this paper was to quantify the relative influence of physical and biological drivers both as separate and interacting factors on the biodegradation kinetics of a soluble substrate. We performed a modeling exercise describing a simplified picture of the 3D soil pore space retaining only the meso- and macroporal space but combining different diffusion pathways in variably saturated conditions and with patchy distributions of bacteria.

We simulated bacterial dynamics in 3D meso- and macropore topologies obtained from X-Ray computed tomography images of undisturbed soil samples at a resolution of $68 \mu \mathrm{m}$. Following the approach found in Chau et al. [33], we first numerically computed explicit air-water interfaces in the pore space using the two-phase two-relaxation-time lattice Boltzmann model (TRT-LBM) [34]. We then simulated the diffusion and biodegradation of a non-sorbing soluble substrate at different water saturation levels under pure diffusive conditions (no water flow due to precipitation). To do so, the advection-diffusion TRT-LBM [35] was coupled to a compartmental model dedicated to bacteria-driven biodegradation, forming the new LBioS model (Lattice-Boltzmann model for Biodegradation affected by soil Structure). We 
built a complete factorial design, in which physical factors ( the geometry of the meso- and macropores, water saturation, bacteria spatialization) and a physiological factor were varied in combination. A global sensitivity analysis was applied to the outputs of 54 generated scenarios. For this exploratory work, our objectives were twofold: i) to assess our modeling approach as a tool for investigating the effect of spatial heterogeneity on biodegradation processes and, ii) to quantify the effect of physical and biological factors on biodegradation kinetics. The simplifications made in this work are presented in details throughout the paper and discussed through their consequences on the obtained results.

\section{LBioS model description}

\subsection{Water physics modeling}

We used a lattice Boltzmann approach for simulating water physics processes. In the lattice Boltzmann method, the physical behavior of a fluid emerges from the microscopic movements of small entities of the fluid - named the populations $\left(f_{q}\right)$ - that are distributed at the nodes or sites $(r)$ of a regular grid - the lattice. Sites belong either to the solid matrix (solid sites) or to the pore space (fluid sites) and are arranged in order to recreate the discrete structure of a porous medium. At every site, populations accounting for microscopic masses and momentum are ascribed to velocity vectors $\left(\overrightarrow{c_{q}}\right)$ defining their direction $(q)$ on the grid $(q=0$ for resting populations and $1 \leq q \leq Q-1$ for moving populations, with $Q$ the number of directions on the grid). We used the Two-Relaxation-Time scheme [35] that takes advantage of the symmetry of the lattice, so that populations $f_{q}$ are decomposed into symmetric and antisymmetric components along their opposite velocities $\overrightarrow{c_{q}}=-\vec{c}_{\bar{q}}$ (equation 1) :

$$
\begin{gathered}
f_{q}=f_{q}^{+}+f_{q}^{-} \text {and } f_{q}^{ \pm}=\frac{1}{2}\left(f_{q}^{ \pm} \pm f_{\bar{q}}\right) \quad q=1, \ldots, Q-1 \\
f_{0}=f_{0}^{+} \quad f_{0}^{-}=0
\end{gathered}
$$

The distribution evolution at the node from time $t$ to $t+1$ is summed up in the equation of evolution (2).

$$
\begin{array}{r}
f_{q}\left(r+\overrightarrow{c_{q}}, t+1\right)-f_{q}(r, t)= \\
\lambda_{e}\left[f_{q}^{+}(r, t)-e_{q}^{+}(r, t)\right]+\lambda_{o}\left[f_{q}^{-}(r, t)-e_{q}^{-}(r, t)\right]+S_{q}
\end{array}
$$


The evolution equation includes the collision operator (two first terms of right hand side of equation 2), a source term $\left(S_{q}\right)$ and the propagation step (left hand side of equation 2). During the collision step, the relaxation of moments resulting from the populations' distribution at time $t$ towards an equilibrium state $\left(e_{q}=e_{q}^{+}+e_{q}^{-}\right)$governs the reorganization of these populations.

During the propagation step, moving populations are translated to their neighboring nodes in the $q$ direction, defining a new distribution at $t+1 . S_{q}$ is an external source term adding or removing a fraction of the population at a given site. It can represent an external force such as gravity, fluid-fluid interactions (cohesion) or biodegradation. Boundary conditions of bounce back type are applied at the pore walls: populations leaving a fluid site and hitting a solid site are sent back in the opposite direction.

Macroscopic variables such as fluid density $(\rho)$ or momentum $(J)$ are calculated at each site of the lattice from the populations' distribution (equations 3 and 4).

$$
\begin{gathered}
\rho=\sum_{q} f_{q} \\
J \Leftarrow \rho \vec{u}=\sum_{q} f_{q} \overrightarrow{c_{q}}
\end{gathered}
$$

where $\vec{u}$ is the macroscopic velocity. They are expressed in lattice units, that can be easily converted into physical units.

The equilibrium populations $e_{0}$ and $e_{q}^{ \pm}$in equation 2 are defined in equations 5-7 from [36].

$$
\begin{aligned}
& e_{0}=\rho-\sum_{q=1}^{Q-1} e_{q}^{+} \\
& e_{q}^{+}=t_{q}^{*} c_{s}^{2} \rho+g_{s} \cdot E_{q}^{+}(\vec{j}, \rho) \quad E_{q}^{+}(\vec{j}, \rho)=\frac{3 j_{q}^{2}-\|\vec{j}\|^{2}}{2 \rho} \\
& \vec{j}=\vec{J}+\frac{\vec{F}}{2} \quad j_{q}=\vec{j} \cdot \overrightarrow{c_{q}} \quad q=1, \ldots Q-1
\end{aligned}
$$




$$
e_{q}^{-}=t_{q}^{*} \vec{u} \overrightarrow{c_{q}} \quad q=1, \ldots \quad Q-1
$$

where $\vec{F}$ is a body force, $c_{s}$ is a free parameter of the model set to $\frac{1}{3}$ and $g_{s}$ is a parameter equal to 0 or 1 . The values of the weights $t_{q}^{*}$, parameters $\lambda_{e}$ and $\lambda_{o}$ and non linear term $E_{q}^{+}(\vec{j}, \rho)$ are specific of the model version (see below).

\subsubsection{Two-phase TRT-LBM}

We used the two-phase TRT-LBM for the resolution of Stokes flow, as described in detail in [34], to simulate air-water distribution in porous media. For modeling the Stokes equation $g_{s}=0$ [36]. The Shan-Chen implementation of multiphase flow was used [37] and the LBM was solved on a D3Q19 lattice (three dimensions, 19 directions), $t_{q}^{*}$ in equations 6 and 7 was set to $\frac{1}{6}$ for orthogonal velocities $\left(\left\|\overrightarrow{c_{q}}\right\|=1\right)$ and $\frac{1}{12}$ for diagonal velocities $\left(\left\|\overrightarrow{c_{q}}\right\|=\sqrt{2}\right)$.

The parameterization of $\lambda_{e}$ and $\lambda_{o}$ is of critical importance for model performance and stability. $\lambda_{e}$ and $\lambda_{o}$ must be comprised between -2 and 0 , their stability range. In the two-phase model, $\lambda_{e}$ is related to the kinematic viscosity $\nu$ along $\nu=-\frac{1}{3}\left(\frac{1}{2}+\frac{1}{\lambda_{e}}\right)$ while $\lambda_{o}$ is set free. We used $\nu=\frac{1}{6}$ and $\lambda_{o}=\frac{3}{16}[34]$.

Rescaling to real physical units can be easily performed taking advantage of the fact that space and time resolutions are linked via $\nu$. Let $L_{L B}$ and $T_{L B}$ be the space and time in lattice units (respectively [lu] and [tu]) and their corresponding value in real units, $L_{P}$ and $T_{P}$ (respectively [L] and [T]). They are linked through equation 8 with $\nu_{L B}$ and $\nu_{P}$ the kinematic viscosity respectively expressed in lattice $\left[\mathrm{lu}^{2} \cdot \mathrm{tu}^{-1}\right]$ and physical units $\left[\mathrm{L}^{2} \cdot \mathrm{T}^{-1}\right]$.

$$
T_{P}=\frac{\nu_{L B} L_{P}^{2} T_{L B}}{\nu_{P} L_{L B}^{2}}
$$

\subsubsection{TRT-LBM for diffusion}

To/simulate the diffusion of a carbonaceous solute in porous media, we used the advection-dispersion TRT-LBM of [35]. The LBM was solved on a D3Q7 lattice. As only diffusion (and not advection) was considered, the macroscopic velocity $(\vec{u})$ was set to zero, so $\operatorname{did} E_{q}^{+}(j, \rho)$ and $e_{q}^{-}$.

$\lambda_{e}$ is set free and $\lambda_{o}$ is related to the molecular diffusion coefficient $D_{M}$ of the solute along $D_{M}=-c_{s}^{2}\left(\frac{1}{2}+\frac{1}{\lambda_{o}}\right)$. We used $D_{M}=\frac{1}{2}$ and $\lambda_{e}=-\frac{64}{33}[38]$. 
As previously, the time resolution of the diffusion LBM was deduced from $D_{M_{L B}}$ in lattice units $\left[\mathrm{lu}^{2} . \mathrm{tu}^{-1}\right], D_{M_{P}}$ in physical units $\left[\mathrm{L}^{2} . \mathrm{T}^{-1}\right]$ and $L_{P}$ in equation 9 .

$$
T_{P}=\frac{D_{M_{L B}} L_{P}^{2} T_{L B}}{D_{M_{P}} L_{L B}^{2}}
$$

\subsection{Biodegradation processes modeling}

The diffusion model was coupled to a biodegradation model deseribing soluble carbon consumption by bacteria. The mathematical formalism of the module was inspired by classical carbon turnover models [39] and relied on the dynamical partition of carbon masses into different pools, i.e. classes of compounds of uniform decomposibility with no other specification than their masses. We did not differentiate organic carbon based on biochemical quality, particle size or stoechiometry as commonly found in decomposition models [39].

We simulated the consumption of a labile, non-sorbing soluble substrate, such as glucose or fructose. We did not address here the hydrolysis of solid organic matter into soluble substrate by exo-enzymes.

Bacteria were represented as full actors of the decomposition as they drive all carbon fluxes in our model (uptake, respiration and mortality). Bacteria were taken hereafter as the only microbial decomposers. We chose to exclude fungi, because they have a different and more complex growth pattern [40].

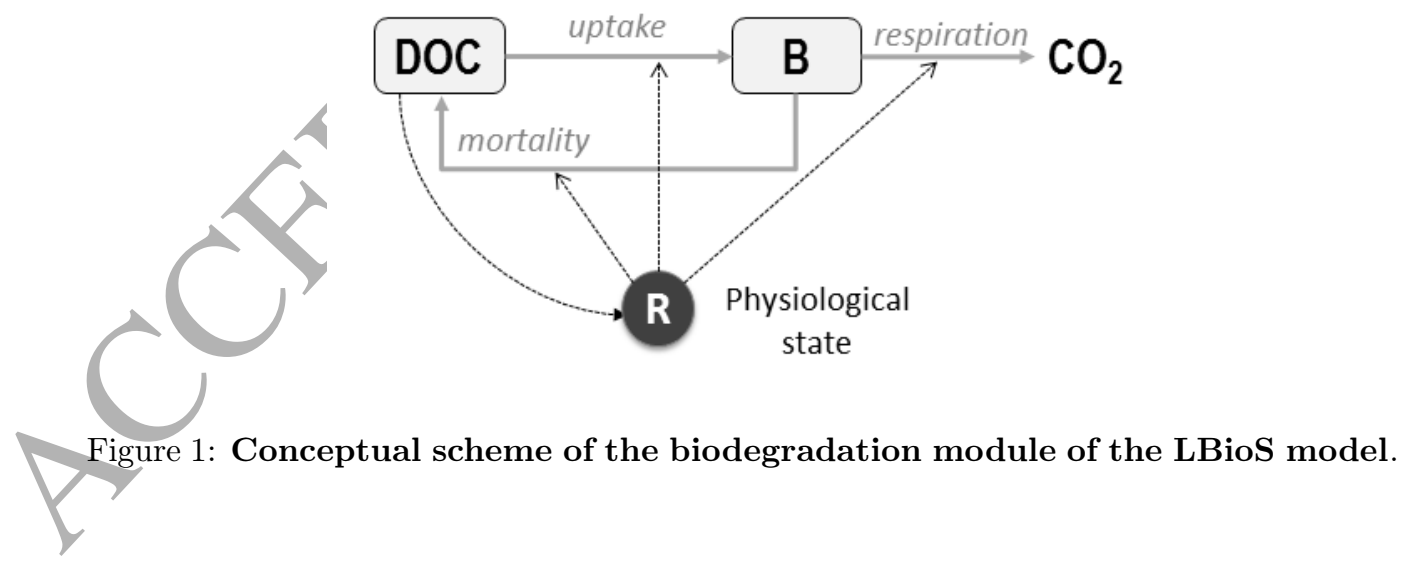

All of the carbon mass was shared between three pools: the dissolved organic carbon $D O C$ which constitutes the pool of available carbon to bac- 
teria, the bacteria $\mathrm{B}$, and the carbon dioxide $\mathrm{CO}_{2}$. All of them are expressed in mass of $\mathrm{C}$ per volume $\left[M . L^{-3}\right]$ (figure 1 ).

The uptake of carbon substrate by bacteria was based on Monod formalism (equation 10).

$$
\operatorname{uptake}(t)=\frac{v_{D O C} D O C(t)}{D O C(t)+k_{D O C}} B(t)
$$

where $v_{D O C}$ is the maximal uptake rate $\left[\mathrm{T}^{-1}\right]$ and $k_{D O C}$ the half saturation constant $\left[\mathrm{M} . \mathrm{L}^{-3}\right]$.

Monod equation was designed for bacterial growth in homogeneous media [41]. Although the environments of the bacterial colonies in the scenarios presented here were not homogeneous, it was felt that this simplification was necessary for a number of reasons: i.) no information is available on how bacterial growth and physiology is affected by differences in microenvironments and, ii.) as a first exploratory step, the aim of the study was not to analyze the interactive effects of abiotic factors and bacterial physiology effect on biodegradation. Therefore, the differences in physiology induced by differences in microenvironment wereneglected.

Bacterial mortality was calculated following equation 11 , where $k_{m}$ is the mortality rate $\left[\mathrm{T}^{-1}\right]$.

$$
\operatorname{mortality}(t)=k_{m} B(t)
$$

Bacteria emit $\mathrm{CO}_{2}$ by respiration. In many carbon turnover models, a portion of the substrate, determined by a constant assimilation yield $Y$, is directly converted into carbon dioxide. Although the latter formulation is more widespread, we simulated respiration as a first-order flux (equation 12), following [26, 42], as it accounts for the direct influence of bacteria on substrate mineralization.

$$
\text { respiration }(t)=k_{r} B(t)
$$

where $k_{r}$ is the respiration rate $\left[\mathrm{T}^{-1}\right]$.

A reversible transition from active to dormant state in response to fluctuating nutrient availability - "the famine-to-feast strategy" - is likely to be crucial in soil systems and therefore in the modeling of microbial dynamics [43]. We integrated a way to account for bacterial activity and dormancy as a function of resource concentration. Bacteria were assumed to fall into a tran- 
sient resting stage during starvation conditions [44]. This strategy enables bacteria to respond to wide nutrient fluctuations as are often found in soils $[10,44,45]$ and not to die off when metabolic requirements cannot be met by the available resources. The physiological state concept and computation (equation 13) were taken from [46] and can also be found in [47].

$$
\frac{d R}{d t}=\frac{v_{D O C} D O C}{k_{D O C}+D O C}\left(\frac{D O C}{k_{i}+D O C}-R\right)
$$

where $R[-]$ is the physiological state index or the instantaneous proportion of active biomass and $k_{i}$ is another half saturation constant, the inhibition constant $\left[\mathrm{M} . \mathrm{L}^{-3}\right]$.

$R$ varies between 0 and 1 as a function of $D \varnothing C . R=1$ describes nonlimiting DOC concentrations. In this case, $100 \%$ of the biomass is active and every bacteria driven flux (uptake, mortality and respiration) reaches its maximum potential value. Lower DOC concentrations result in the reduction of the bacterial fluxes by a factor $R$. The optional activation of $R$ is useful for assessing the role of dormancy in DQC transformation kinetics.

The ordinary differential equations of the pools of the biodegradation module are given below:

$$
\begin{gathered}
\frac{d D O C}{d t}=-\frac{v_{D O C} D O C}{k_{D O C}+D O C} R B+k_{m} R B \\
\frac{d B}{d t}=\left(\frac{v_{D O C} D O C}{k_{D O C}+D O C}-k_{r}-k_{m}\right) R B \\
\frac{d C O_{2}}{d t}=k_{r} R B
\end{gathered}
$$

2.3. Coupling of the diffusion TRT-LBM and the biodegradation module

In the LBM, the lattice sites are assigned as fluid or solid sites to reproduce the geometry of the soil pore space. The site's class specifies the physical and biochemical processes that can take place in.

DOC moves within the medium by diffusing in the liquid phase (i.e. the fluid sites). The diffusion of DOC is managed by TRT-LBM by redistributing the DOC mass of each fluid site according to the microscopic populations using the weights $t_{q}^{*}$ (equation 17). 


$$
f_{q}(r, t)=t_{q}^{*} \operatorname{DOC}(r, t) \quad q=0, \ldots Q-1
$$

Bacteria were immobile and placed in the fluid sites (more details are provided in section 3.4.1). The local fluxes of DOC emanating from the bacterial metabolism constitute the source term $S_{q}$ in the TRT equation of evolution (2). They are proportionally redistributed to the microscopic populations $\left(f_{q}\right)$ along:

$$
S_{q}(r, q, t)=t_{q}^{*} \quad(-\operatorname{uptake}(r, t)+\operatorname{mortality}(r, t))
$$

Bacterial growth therefore relies on the supply of substrate, itself dependent on diffusion processes within the pore network.

\section{Factorial design of soluble carbon substrate biodegradation}

\subsection{Generation of $3 D$ soil sample images}

\subsubsection{Soil column sampling and scanning}

The soil is a silty loamy (19\% clay, $75 \%$ silt, $6 \%$ sand) Albeluvisol [48] from a field experiment in Feucherolles (50 km West of Paris, France). It is cultivated (wheat-maize succession), tilled, fertilized and manured with urban compost [49]. A soil column (5 cm height, $5 \mathrm{~cm}$ diameter) was collected from the tillage inter-furrows [50]. The soil samples were scanned with a benchtop X-ray micro-computed tomography system (Nikon Metrology XTek HMX CT scanner, Nikon Metrology X-Tek Systems Ltd, Tring, UK) at $90 \mathrm{keV}$ and $112 \mathrm{~mA}$. The 3D image made of $600 \times 600 \times 600$ voxels was reconstructed using the CT Pro reconstruction software and a voxelresolution of $68 \mu \mathrm{m}$ was achieved corresponding to a volume size of about $68 \mathrm{~cm}^{3}$. A global threshold according to [50] was used to discriminate solid matrix from pore space.

To maintain computational and memory cost at reasonable levels, we divided the initial image into 216 cubes of $100 \times 100 \times 100$ voxels (of volume size of about $314 \mathrm{~mm}^{3}$ ). While the total macroporosity of the large image (i.e. the proportion of void voxels above $68 \mu \mathrm{m}$ resolution) was 0.11 [50], there was a large variation of the macroporosity across the 216 cubes (with a coefficient of variation of $106 \%$ ) as well as a large variation of the pore topologies. Three cubes with different pore topologies were selected for the study. The choice of cubes was based on the morphological characteristics of their pore space. 


\subsubsection{Representativeness of the soil images}

Our objective was to reproduce millimeter scale variability identified by several authors $[3,7]$. As resolution and sample size are not independent with computed tomography scanning, we chose to use a relatively coarse resolution $(68 \mu \mathrm{m})$ in order to image relatively large samples and therefore account for environmental variations at the millimeter scale.

Since the soil consists to $94 \%$ out of silt and clay, i.e., particles of size < $50 \mu \mathrm{m}$ the resolved porosity of the $\mathrm{CT}$ images corresponds to a volumetric water content measured on the whole soil column of only $0.14 \mathrm{~cm}^{3} . \mathrm{cm}^{-3}$ while for the unresolved porosity it amounts to about $0.40 \mathrm{~cm}^{3} \cdot \mathrm{cm}^{-3}$ [50]. At the resolution of the scans, the CT images are not accounting for pores or any geometrical feature smaller than $68 \mu \mathrm{m}$. They only depict the topology of meso- or macropores according to Luxmoore classification 151]. Nevertheless, as will be evidenced in next section, straightforward visual inspection and quantification of morphological indicators demonstrate that they captured more realistically the 3D geometry and topolggy of soil meso- and macropores than would generic porous media models like thøse based on sphere packings. Indeed, the investigated pores are the result of tillage since the soil was sampled in the former soil surface that was plowed in by the mouldboard. The maize residues that were incorporated also participated to the formation of such pores. A micro-morphological study of the soil sample was previously performed on the soil sample [50], which found very good agreement between the shape of meso- andmacropores detected by the scans (at least on the 2D sections) and that identified on thin-sections.

\subsubsection{Selection of three $100^{3}$ voxels cubes}

We used three indicators to assess the physical heterogeneity of the pore space topology: the Euler-Poincare characteristic (EPC), the geometrical tortuosity $(\tau)$ and the specific surface area (SSA).

A preliminary treatment of the cubes was performed to remove all disconnected pores (small pores can be isolated because of artificial edge cutting or because some connections may not be detected at the given resolution) using a home-made algorithm for searching connected components. Prior to carrying out the morphological analyses on which the cube selection was based, all cubes that did not have connected porosity from the top $(Z=1)$ to the bottom $(Z=100)$ planes were removed. Of the remaining 61 cubes, we randomly selected ten cubes (named after $G_{1}$ to $G_{10}$ ) that spanned the whole range of porosity, and performed on them the morphological analyses. We 
further calculated the three morphological indicators on a periodic synthetic porous medium: a cubic packing of spheres of $100^{3}$ voxels, named after $S P$. It was made of $4 \times 4 \times 4$ entire spheres (10 lu radius) and $2 \times 4 \times 4$ half spheres placed at the edges. The porosity of SP was $39.78 \%$.

The Euler-Poincaré characteristic. The Euler-Poincaré characteristic(EPC) is used to quantify the connectivity of the pore space, i.e. the number of non-redundant closed-loop paths in the pore space geometry [52]. We used the method described in [53] for calculating the EPC on the segmented 3D images. The first step was a morphological opening of the pore space (i.e. successive erosion and dilation) using ImageJ software (Minimum 3D and Maximum 3D filters) performed on the full 3D stack of images of each cube. The procedure was repeated with the pixelized 3D stracturing element (sphere) of increasing radius (from one to eight pixels). We thus obtained eight 3D images of each medium, where pores from small to large diameter were successively removed. For each image, we calculated the remaining porosity. Figure $2 \mathrm{a}$ shows the resulting pore-size distributioni (PSD). The PSD curves of the ten cubes showed that the equivalent pore diameters were comprised between 68 and $3536 \mu \mathrm{m}$ ranging the pores as meso- and macropores according to Luxmoore classification [51]. Only one cube $\left(G_{1}\right)$ exhibited pores of diameter smaller than $544 \mu \mathrm{m}$ while the maximum size of $S P$ pores was 952 $\mu m$.

We calculated the third Minkowski functional measure from which the Euler-Poincaré number can be derived, using algorithms based on Ohser and Mücklich $[32,54,55]$. Results are shown in figure 2b. The EPC curve of $S P$ was characterised by high negative and positive values together with an abrupt variation between both values. The latter was the result of simultaneous closing of all connections - in only two opening steps from 544 to $816 \mu \mathrm{m}$ diannete - changing from a pore phase well connected by multiple paths to a set of isolated cavities. By contrast, the cubes exhibited a lower connectivity but a continuous variability in the EPC curve as observed for non-aggregated soils [53]. The EPC curves of several cubes showed negative values at small radii and reached 0 at larger radii, suggesting a continuous well-connected pore space. In some cases, (cubes $G_{10}, G_{6}, G_{8}$, figure $2 \mathrm{~b}$ ), the EPC curve reached positive values suggesting that the openings generated a number of isolated cavities that exceeded the number of loops. It has been suggested that this form of EPC curve is indicative of larger pores connected only by smaller pores or throats [53], as is the case for the sphere packing. 
Finally, other cubes presented flat EPC curves always close to zero $\left(G_{1}, G_{4}\right)$ or slightly positive $\left(G_{3}\right)$ suggesting a poorly connected pore network and a low variation in the geometry of the pore space for the whole range of pore size [53]. 

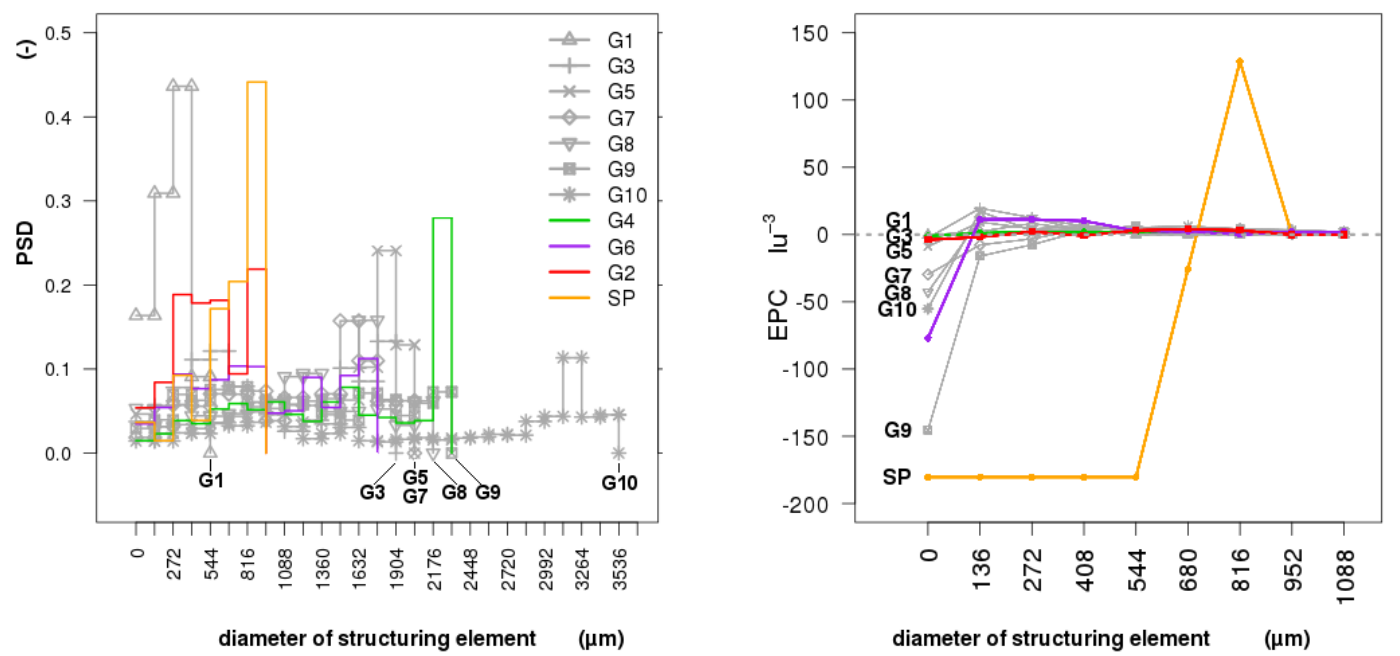

diameter of structuring element $\quad(\mu \mathrm{m})$

(a)

(b)

Porosity (\%)

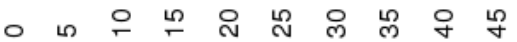

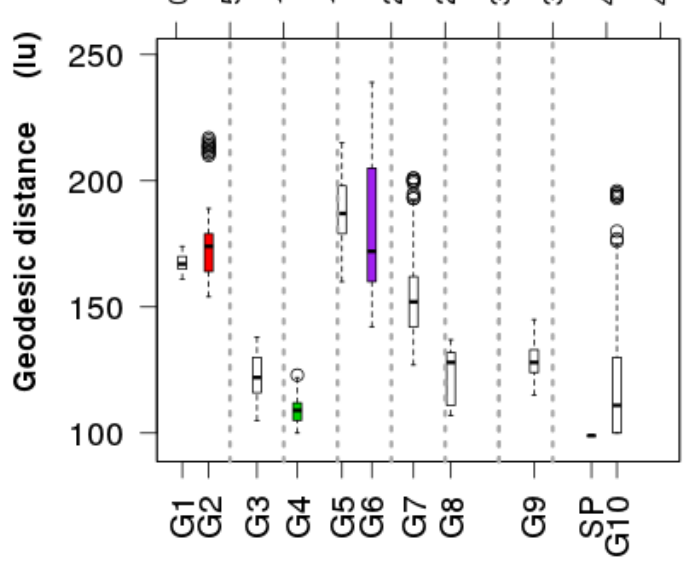

(c)

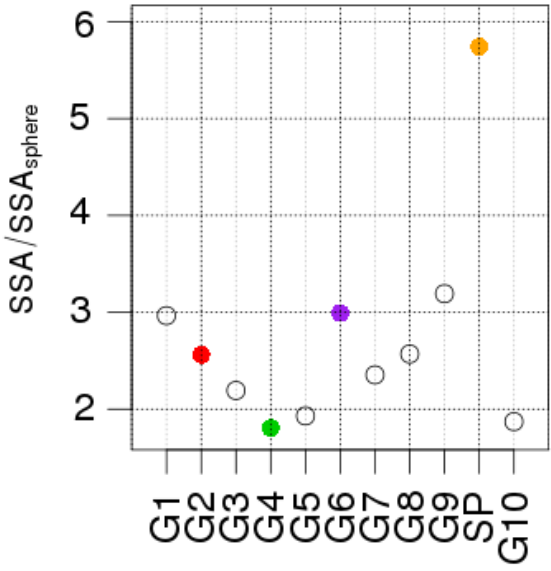

(d)

Figure 2: Morphological indicators of the ten $100^{3}$ voxels images and the sphere packing $(S P)$ : the pore-size distribution (a), Euler-Poincaré characteristic (b), geodesic distance (c) and the ratio of SSA of the cubes and SSA of sphere of equivalent pore volume (d). $S P$ and the three cubes $\left(G_{4}, G_{6}, G_{2}\right)$ chosen among the initial selection of ten are shown in color. 
The geometrical tortuosity. We calculated the geometrical tortuosity, $\tau_{g}$, which is defined as the ratio of the geodesic distance, $L_{g}$, over the Euclidean distance, $L_{e}$ [56]. It describes the larger diffusional pathways occurring in the sinuous shape of the pore network as compared to free water. Following Gommes et al. [57], we calculated the geodesic distances from the topmost plane $(Z=1)$ to any point of the pore space of the cube using a 6 -connectivity algorithm. Figure 2c shows only the results of the geodesic distances of the points of the plane $Z=100$ for the ten cubes, since geodesic distances between closer points may not be relevant to the effective diffusion transport properties of the whole cube [57].

The mean geodesic distance and the dispersion of the data differed considerably among the ten cubes 2c). Some cubes were also characterized by low values close to 100 (i.e. geometrical tortuosity close to 1), which suggests potentially short diffusion pathways $\left(G_{4}, G_{3}\right)$. Other cubes were characterized by larger geometrical tortuosity values of about $1.5\left(G_{1}, G_{2}, G_{5}, G_{6}\right)$, large dispersion of the geodesic distances $\left(G_{6}, G_{10}\right)$, with frequent extreme values $\left(G_{2}, G_{7}, G_{10}\right)$. This is probably related to a well-connected pore space with a lot of non-redundant loops, suggesting a more complex shape of the pore space geometry and potentially tortuous diffusion pathways. By contrast, for the sphere packing all the calculated geodesic distances $L_{g}$ were found equal to $100 \mathrm{lu}$, the Euclidean distance $L_{e}$ (figure 2c).

The specific surface area. Finally, the specific surface area (SSA) describes the available liquid/solid interface where bacteria can attach and live. It is defined as the liquid/solid interface area per unit mass [52] and was straightforwardly calculated as the ratio between boundary solid sites and total solid sites of the cube images. In order to easily compare the ten cubes and $S P$, we normalized the SSA by the SSA of a sphere of equivalent porosity (figure $2 \mathrm{~d})$.

All cubes had twice to three times larger specific surface area than spheres of equivalent volumes, while for $S P$ it was almost six times, because of the spherical shape of the solid grains that maximized the surface area between the liduid and solid phases by contrast to the CT images that displayed more concave surfaces. The cubes with the lowest SSA ratios were expected to have large uniform pores $\left(G_{4}, G_{5}, G_{10}\right)$, while high SSA ratios probably denoted abundant small pores and/or irregular patterns of the liquid/solid interface $\left(G_{1}, G_{6}, G_{9}\right)$. 
The comparison with $S P$ showed significant differences in the morphological indicators as compared to the ten cubes. In particular, the irregular pore shapes observed in the CT images caused anisotropic and tortuous diffusion pathways that could not be found in SP. The CT images appeared thus as good candidates to test how LBioS can describe in a deterministic way the biodegradation kinetics at the millimeter scale, when taking into account realistic spatial disconnection between DOC and hot-spots of bacterial colonies $[7,58]$ at different levels of water saturation.

We selected three cubes for which the three morphological indicators suggested that the heterogeneity of the pore network was either high, intermediate or low. The most homogeneous medium was the cube $G_{4}$ as indicated by the low and constant EPC values, the lowest geometrical tortuosity and surface specific area ratio. From visual observation, it is characterized by a unique large pore, straight in the vertical direction and connected with small lateral pores (figure 3 ). Cube $G_{6}$ was selected because it obtained values of geometrical tortuosity and SSA ratio among the highest found. It is made of two main irregular pores (a massive one in the top half and a smallest one in the bottom half) connected by a unique junction. The presence of a fine elongated pore, from $Z \approx 35$ to $Z \approx 80$ length units $(Z \approx 2380-5440 \mu \mathrm{m})$, connected by a narrow throat probably participated to the sign shift of the EPC curve.

Compared to $G_{6}, G_{2}$ presented a lower SSA ratio, a similarly high geometrical tortuosity and a rather flat EPC curve with low negative values showing thus contrasted values of the three morphological indicators. The visual observation of $G_{2}$ revealed an anisotropy for diffusion in the vertical direction. Indeed, it is characterized by a funnel-shaped pore topology, with a wide pore at the top (maximum width $\approx 40$ lattice length units or 2700 $\mu \mathrm{m}$ ) ending with a narrow extension (length $\approx 40 \mathrm{lu}$ or $2700 \mu \mathrm{m}$, minimal throat size: 5 lu or $340 \mu \mathrm{m}$ ) (figure 3 ). Total macroporosity values for $G_{4}$, $G_{6}$ and $G_{2}$ were $11.25 \%, 18.82 \%$ and $3.02 \%$ respectively.

\subsection{Generation of water-air distributions for three saturation levels}

For each cube, we calculated the distributions of water and air corresponding to different saturation indexes (i.e. the proportion of liquid voxels on porous voxels): $S_{w}=1, S_{w}=0.5$ and $S_{w}=0.25$. The original images of pore space were used for the complete saturation $(S w=1)$. The lower saturation levels were produced by simulating phase separation in pore space with the two-phase TRT-LBM. Phase separation was induced by initially 
setting a homogeneous macroscopic fluid density $\left(\rho_{0}\right)$ to the porous sites of the lattice according to [34]. The initial density $\left(\rho_{0}\right)$ was calculated using equation 19.

$$
\rho_{0}=S_{w} \rho_{L}+\left(1-S_{w}\right) \rho_{G}
$$

where $\rho_{L}$ and $\rho_{G}$ are respectively the theoretical density values of liquid and gas phases given in [34]. Simulations were run until equilibrium was reached $\left(T_{f}=5000\right.$ time units $\left.\approx 3.825 \mathrm{~s}\right)$. Note that the space resolution of the images gave a time resolution of $T_{P}=0.765 \mathrm{~ms}$ according to equation 8 .

The simulated static distributions of water and air phases are displayed in figure 3. As water saturation decreased, bubbles of increasing size were found in the center of the biggest pores. 

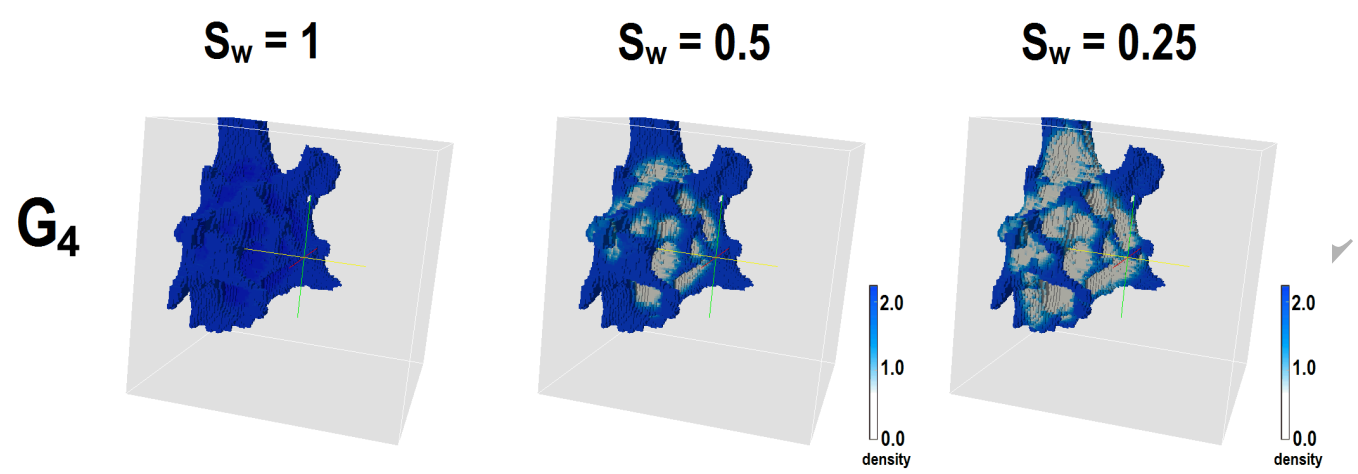

\section{$\mathrm{G}_{6}$}
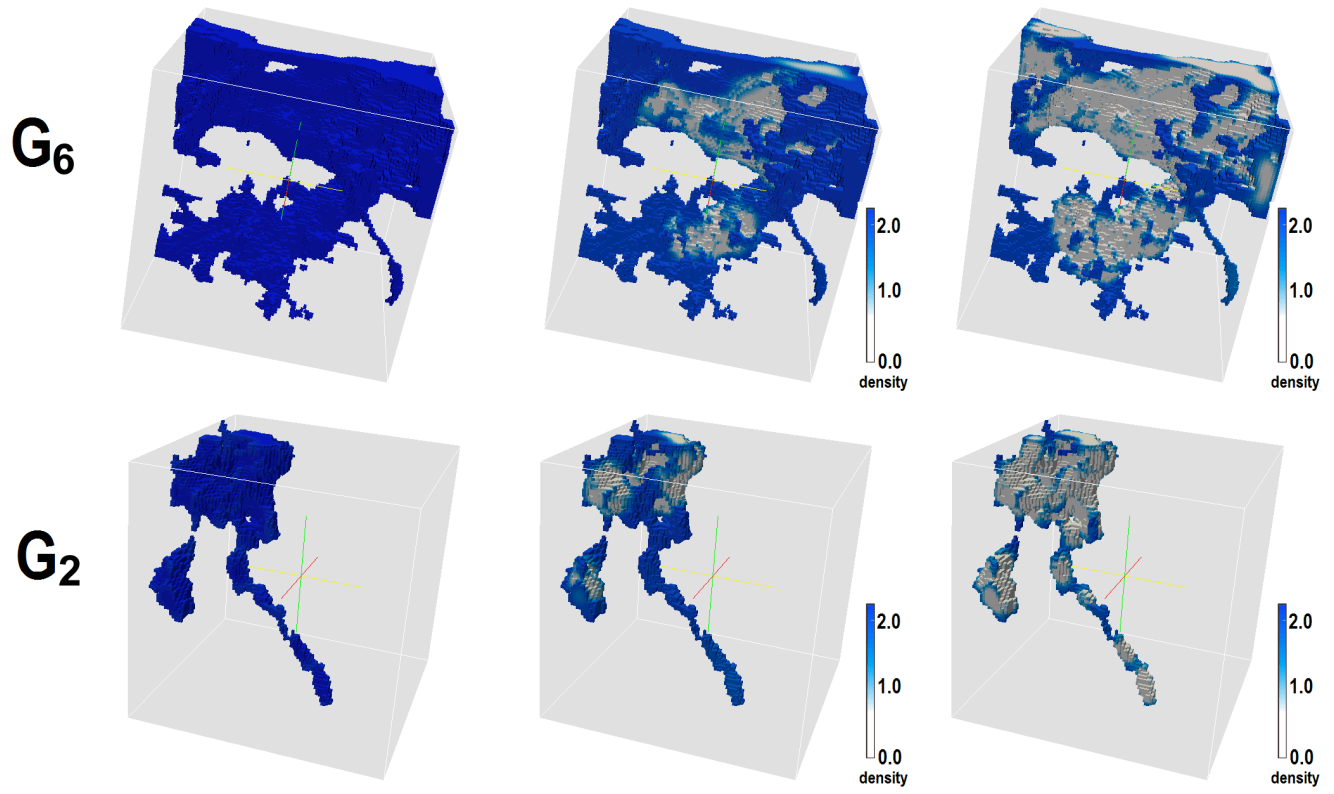

Figure 3: Pore space geometry and water and air distribution in the three selected media $\left(G_{4}, G_{6}, G_{2}\right)$ at the three simulated saturation levels $\left(S_{w}=1, S_{w}=0.5, S_{w}=0.25\right)$. The liquid phase is in dark, and the gas phase is in light. Solid phase is not represented. Note that all pore space connected from first $(Z=1)$ to last $(Z=99)$ plane in the vertical direction for all cubes.

\subsection{Effective diffusion in the $3 D$ porous media}

For each saturation level, we simulated the diffusion of a tracer in the three selected cubes in order to better characterize the diffusion transport properties than can be deduced from the geometrical tortuosity alone. To prevent periodic conditions, three faces of the cubes (planes $X=100, Y=100$ and 
$Z=100)$ were set as solid. At $t=0$ the tracer mass was set to $M=M_{0}$ at $Z=1$, and $M=0$ everywhere else. The initial conditions constrained the diffusion in the vertical axis and, following [59], we compared the simulated tracer mass $M(z, t)$ to the analytical solution of the diffusion equation (20) written for a semi-infinite medium and previous initial conditions according to [60] and for a variably saturated porous medium:

$$
M_{t h}(z)=\frac{M_{0}}{\sqrt{\pi D_{e} t / \theta}} \times \exp \left(-\frac{\left(z-z_{0}\right)^{2}}{4 D_{e} t / \theta}\right)
$$

where $D_{e}$ is the effective diffusion coefficient $\left[\mathrm{L}^{2} \cdot \mathrm{T}^{-1}\right], \theta$ is the volumetric water content $\left[\mathrm{M}^{3} \cdot \mathrm{M}^{-3}\right], z$ is the vertical coordinate, $Z_{0}=1$ and $t$ is the computation time large enough for the tracer plume to diffuse through a large part of the porous medium but small enough to keep a zero mass on the $Z=99$ plane to keep close to the semi-infinite conditions of the analytical solution. From the 3D maps of tracer mass at each time step, we calculated the total mass by plane $Z, M(z, t)=\sum_{r \in Z} \Sigma_{q} f_{q}$.

The optimization of the effective diffusion coefficient $D_{e}$ was done by minimizing the L2 norm error $E_{L}$ (equation 21).

$$
E_{L}=\sqrt{\frac{\sum_{r}\left[M_{t h}(z)-M(z)\right]^{2}}{\sum_{r} M_{t h}(z)^{2}}}
$$

Results are presented in figure 4. A large uncertainty was associated to the optimization with large values of $E_{L}$ found in all cases. The effective diffusion coefficient and $E_{L}$ values gave complementary information about the heterogeneity of the diffusion pathways. A large $D_{e}$ value indicated a rather homogeneous topology presenting few constraints on solute diffusion. The larger the $E_{\mathrm{L}}$ value, the more the tracer profile diverged from the Gaussian shape (equation 20), because of heterogeneous diffusion pathways. 

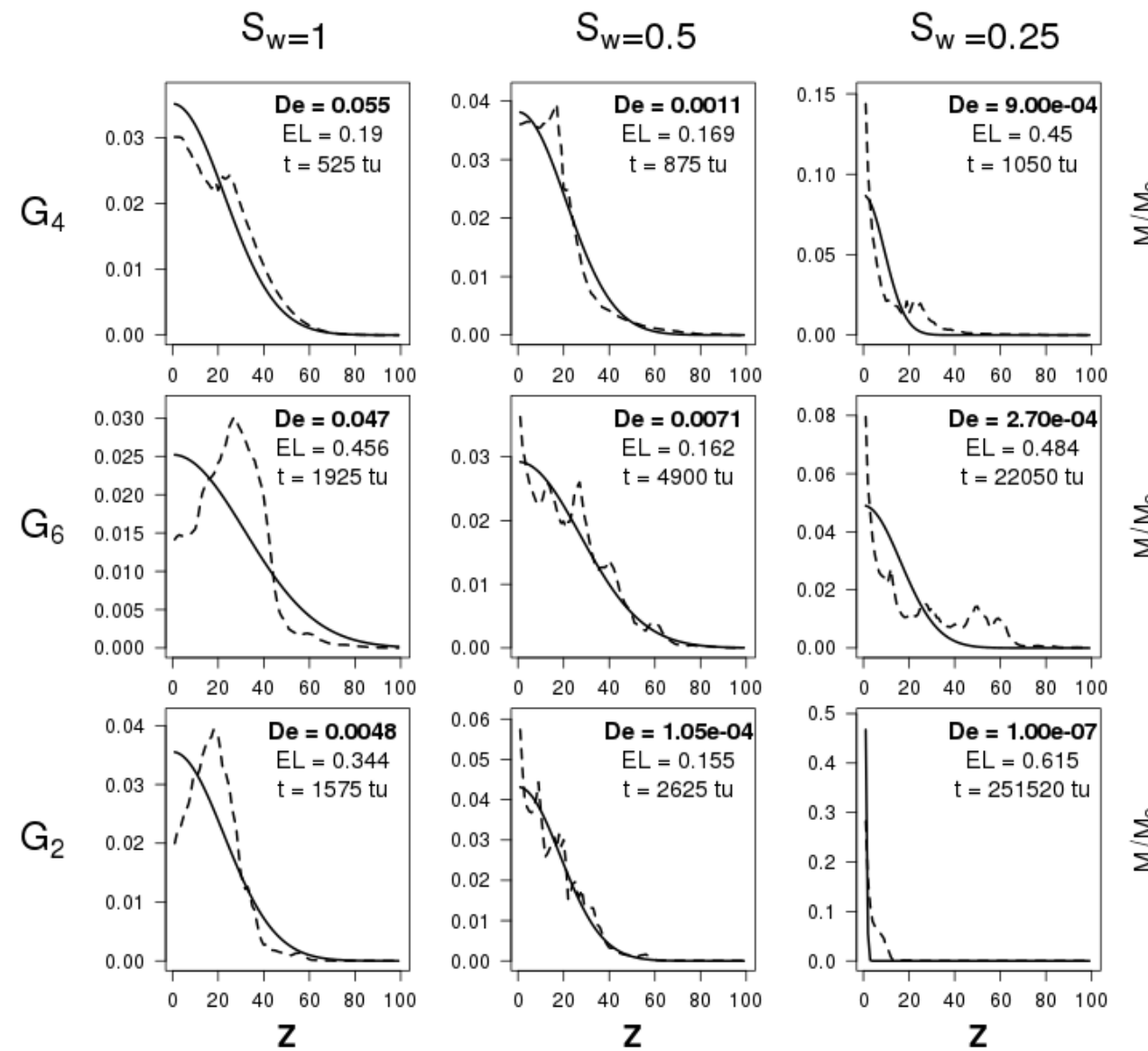

Figure 4: Comparison between the relative analytical mass calculated from equation 20 (plain lines) and the relative simulated mass profile along $\boldsymbol{Z}$ (dashed lines) in the three media at saturation levels of $S_{w}=1, S_{w}=0.5, S_{w}=0.25$. Masses (in lattice mass units) are normalized by the initial mass of the tracer pulse, $M_{0}$.

The effective diffusion was affected by both the geometry of the pore network and the saturation level. Under complete saturation, the cubes could be ranked by decreasing effective diffusion rates, with $G_{4}>G_{6}>G_{2}$. This order was kept whatever the saturation level, and the difference among cubes increased as a function of decreasing saturation level.

In $G_{4}$, the tracer profile was in rather good agreement with the theoretical Gaussian shape, confirming the values found for the morphological indicators. By contrast, in $G_{2}$ and $G_{6}$, even under complete saturation, the tracer profiles 
diverged from the Gaussian shape, suggesting many more variations in pore section and heterogeneous diffusion pathways than in $G_{4}$ (figure 3 ). In $G_{2}$, the solute did not diffuse beyond $Z=20$ because of discontinuities in the water phase at this depth. This discontinuity resulted from the coarse discretization of the grid that did not allow for thin water films, as was also observed by Vogel et al. [24].

\subsection{Biodegradation kinetics in the 3D porous media}

\subsubsection{Design of the numerical simulations}

We computed the biodegradation of a mass $D O C_{0}$ of DOC during ten days (about 250,000 lattice time units). Substrate input was performed as in the previous section (3.3), by replacing the tracer solute by DOC.

In this work, we intended to reproduce patchy, distributions of bacteria or hot-spots. Because of the coarse resolution and the biodegradation module written in terms of carbon pools, we did not simulate the spatial expansion of bacterial biomass: the growth was only calculated as an increase of carbon mass in the initialized voxels. Note that we checked in our simulations that we did not reach unrealistic biomass density in these voxels. We did not simulate biofilms that can alter fluid transport properties of the host porous medium through bio-clogging processes [61] because there is little evidence that biofilms develop extensively in natural soils (e.g. [62]). Therefore we neglected the potential feedback that bacterial activity can have on the physical heterogeneity of the pore networks.

We thus split the initial total mass of the bacteria pool, $B_{0}$, into several spots that were always water-filled whatever the saturation level. The sites at the boundary with solid mostly contained the remaining water at low saturation level. We thus selected these sites to hold the bacteria spots because we did not want to modify their position when we modified the water saturation level. However, due to the coarse discretization of the grid, some of the sites neighboring the solid phase may be empty of water, so that we initially retained the boundary sites that remained full of water at the lowest saturation level.

The modeled distributions of bacteria were based on results from studies which suggest that spots of bacterial activity can be separated by few hundreds of microns [63] to millimetric [64] or even centimetric distances [3, 4]. We generated three spatial arrangements with different inter-spots spacing and mean distances to the substrate source, at a submillimeter scale. The 
initial biomass $\left(B_{0}\right)$ was split into ten spots of equal carbon mass. A homogeneous distribution throughout the vertical axis of the cube was compared to two spatial arrangements with bacterial spots concentrated either close to the DOC source or far from it. In the Dispersed location $\left(L_{D}\right)$, spots were regularly spaced along the $Z$ direction (one spot every $10 \Delta Z=10$ lu $=680$ $\mu \mathrm{m})$. In the Top $\left(L_{T}\right)$ and Bottom locations $\left(L_{B}\right)$, bacterial sites were placed every $\Delta Z=3 \mathrm{lu}=204 \mu \mathrm{m}$, on $Z<30 \mathrm{lu}=2,040 \mu \mathrm{m}$ and $Z>70 \mathrm{lu}=$ $4,760 \mu \mathrm{m}$, respectively.

\subsubsection{Biodegradation module parameterization}

Values of the parameters of the biodegradation module (table 1) were obtained from two papers: [42, 47]. Monga et al. incubated single Arthrobacter $s p$. strains in unsaturated sand $(\theta=0.33)$ amended with fructose [42]. As glucose has been found not to interact with the soil matrix in [65], we assumed that fructose does not either, as it is an isomer of glucose. We used the same biodegradation model as [42] (without dormancy) and applied the rate constants $\left(v_{D O C}, k_{D O C}, k_{r}, k_{m}\right)$ they fitted to experimental $\mathrm{CO}_{2}$ emission curves.

The initial masses of substrate $D O C_{0}$ and bacteria $B_{0}$ were identical to those of [42] for all cubes and water saturation levels so that concentrations changed between the scenarios because of the differences in water volume.

The parameters $\left(k_{i}\right.$ and $\left.R_{0}\right)$ used for computing the physiological state were found in [47]. Two inhibition constants values $\left(k_{i_{r}}\right.$ and $\left.k_{i_{K}}\right)$ characterize respectively rapid litter decomposers or $r$-strategists and slow decomposers (K-strategists). Ingwersen et al. assimilated soil bacteria to rapid decomposers [47]. We thus applied $k_{i_{r}}$. Soil is characterized by low microbial activity, due to fluctuating and fragmented resource input [43]. The estimated proportion of active biomass under natural conditions in soils ranges between 5 and $20 \%(18.8 \%+/-8.8$ was found in [66], 5 to $20 \%$ in [67] or 18 $\%+/-15$ in [68]). An initial value of $R=10 \%$ was chosen [47] in agreement with the above-mentioned references.

The impact of bacterial physiology on biodegradation kinetics was assessed by calculating the dynamical physiological state $R$ (equation 13) in one case $\left(P_{1}\right)$. In another case, $P_{0}$, the physiological state was set to a constant value of 1 , standing for optimal resource abundance conditions. 


\begin{tabular}{|c|c|c|c|c|}
\hline Symbol & Definition & LB parameter & Physical parameter & Ref. \\
\hline $\begin{array}{c}D_{M} \\
v_{D O C} \\
k_{D O C} \\
k_{r} \\
k_{m} \\
k_{i} \\
R_{0} \\
D O C_{0} \\
B_{0}\end{array}$ & $\begin{array}{l}\text { DOC mol. diff. coeff. } \\
\text { Maximal uptake rate } \\
\text { Half saturation constant } \\
\text { Respiration rate } \\
\text { Mortality rate } \\
\text { Inhibition constant } \\
\text { Initial physical state } \\
\text { Initial DOC mass } \\
\text { Initial bacterial mass }\end{array}$ & $\begin{array}{c}0.5 \mathrm{lu}^{2} . \mathrm{tu}^{-1} \\
6.76 \times 10^{-4} \mathrm{tu}^{-1} \\
1.57 \times 10^{-10} \mathrm{mu}^{-\mathrm{lu}^{-3}} \\
7.95 \times 10^{-6} \mathrm{tu}^{-1} \\
5.96 \times 10^{-5} \mathrm{tu}^{-1} \\
1.91 \times 10^{-8} \mathrm{mu}^{-1 u^{-3}} \\
0.1[-] \\
5.89 \times 10^{-3} \mathrm{mu} \\
1.24 \times 10^{-8} \mathrm{mu}\end{array}$ & $\begin{array}{c}6.73 \times 10^{-6} \mathrm{~cm}^{2} \cdot \mathrm{s}^{-1} \\
17 \mathrm{~d}^{-1} \\
5 \times 10^{-4} \mathrm{mgC} \cdot \mathrm{cm}^{-3} \text { water } \\
0.2 \mathrm{~d}^{-1} \\
1.5 \mathrm{~d}^{-1} \\
6.07 \times 10^{-2} \mathrm{mgC} \cdot \mathrm{cm}^{-3} \text { soil } \\
0.14-] \\
5.89 \times 10^{-3} \mathrm{mgC} \\
1.24 \times 10^{-8} \mathrm{mgC}\end{array}$ & $\begin{array}{l}{[69]} \\
{[42]} \\
{[42]} \\
{[42]} \\
{[42]} \\
{[47]} \\
{[47]} \\
{[42]} \\
{[42]}\end{array}$ \\
\hline
\end{tabular}

Table 1: Parameters of the biodegradation module. lu is lattice length unit, tu is time unit and mu is mass unit.

\section{Global sensitivity analysis}

A global sensitivity analysis [70-72] was carried out to study the sensitivity of three model outputs to four input factors. The model outputs were $D O C, B$ and $\mathrm{CO}_{2}$ at two time steps (three days and ten days), and the four input factors were those presented above: Geometry $(G)$, Saturation $(S)$, Location $(L)$ and Physiology $(P)$. Three levels were considered for the first three input factors and two levels for the last one. These levels correspond to discrete values of the factors. A complete factorial design was built by combining all the levels across all the factors leading to $3 \times 3 \times 3 \times 2=54$ scenarios.

An analysis of variance was performed with the aov function of the $R$ software 173. The total variability found in the values of the output variables was thus decomposed into contribution parts of the four factors and of all of the combinations between those factors.

The variance distribution was related to a reference case to which the other scenarios were compared. The scenario with the most homogeneous conditions was designated as the reference scenario. $G_{4}$ at Saturation $S_{w}=1$ displayed the most homogeneous conditions for diffusion (section 3.3). The Dispersed location is characterized by the most even bacteria repartition and the $P_{0}$ physiology modality by a constant and optimal bacterial activity. We thus chose as the reference scenario, the combination between modalities 
$G_{4}$ for geometry, $S_{w}=1$ for saturation, Dispersed for location and $P_{0}$ for physiology.

Finally, in order to determine whether the relationship between the model outputs and the distribution of bacterial hotspots was general or dependent on the specific location of the hotspots within the pore network, we performed five additional random selections of $X$ and $Y$ coordinates for the fixed $Z$. Bacterial kinetics were simulated for all of these selections at $S_{w}=0.25$ and physiology $P_{1}$, for which the largest contrast in outputs was expected. The coefficients of variation of the $D O C$ outputs from the five random selections were calculated at ten regular time steps during the whole simulation period (251,520 time units or ten days) and then averaged over all time steps.

\section{Results}

\subsection{General features of bacterial growth kinetics}

The same DOC input resulted in a large variety of outputs in the 54 scenarios, as reflected by high coefficients of variation (table 2 and figures 5 - 8; comprehensive kinetic results can be found in appendix A.11). The final situations ranged from zero biodegradation (e.g. figure 6b, dashed-dotted lines) to nearly complete substrate depletion (e.g. figure 8a, dashed lines). Some of the scenarios were close to the "classical" growth pattern found for labile soluble substrates in optimal growth conditions [74]. After a lag phase, biomass grew exponentially until substrate depletion then declined due to reduced uptake and C losses by mortality and respiration, as reflected by the high $\mathrm{CO}_{2}$ emissions (e.g. figure 5, plain lines). Other scenarios diverged from this behavior. In some case biomass growth was rapidly limited despite the fact that the overall DOC concentrations were still sufficient to sustain growth (figure $6 \mathrm{~b}$, dotted lines). In these cases, a large portion of the DOC remained unconsumed until the end. No growth was observed in an extreme case of limitation (figure $6 \mathrm{~b}$, dashed-dotted lines).

\subsection{Influence of biological and physical factors}

Physiology. The activation of physiological state modulated kinetics (figure 5). Dormancy increased the range of durations of the lag phase (16 to 54 hours for scenarios with $P_{1}$ versus 19 to $25 \mathrm{~h}$ for $\left.P_{0}\right)$. Growth often resulted in a biomass plateau and reduced $\mathrm{CO}_{2}$ emission when the physiological state $(R)$ variation was considered (scenarios $P_{1}$ ) because $\mathrm{C}$ stayed in the increasingly inactive biomass pool as $R$ decreased. By contrast, biomass was more prone 


\begin{tabular}{|c|c|c|c|}
\hline & $\boldsymbol{D O C}$ & $\boldsymbol{B}$ & $\boldsymbol{C O}_{2}$ \\
\hline Mean & 0.173 & 0.362 & 0.464 \\
$\min$ & 0.015 & $1.56 \times 10^{-6}$ & $8.50 \times 10^{-8}$ \\
$\mathbf{m a x}$ & 1.00 & 0.614 & 0.798 \\
$\mathbf{C V}$ & 1.313 & 0.527 & 0.444 \\
\hline
\end{tabular}

Table 2: Summarized final values of the three carbon pools (expressed as $\mathrm{C} / \mathrm{C}_{0}$ )

to decline when respiration and mortality were not reduced by $R$ (scenarios $\left.P_{0}\right)$. It resulted in a systematically lower final biomass value after ten days in these scenarios $\left(25 \%\right.$ in average for $P_{0}$ compared to $52 \%$ for $P_{1}$ ). The physiological state activation also enhanced DOC uptake efficiency (16\% of initial DOC was left over after ten days in average for scenarios $P_{1}$ versus $21 \%$ for $\left.P_{0}\right)$. This effect was especially apparent for the most homogeneous conditions (e.g. for cube $G_{4}$ and for high saturation levels, see figure 5).

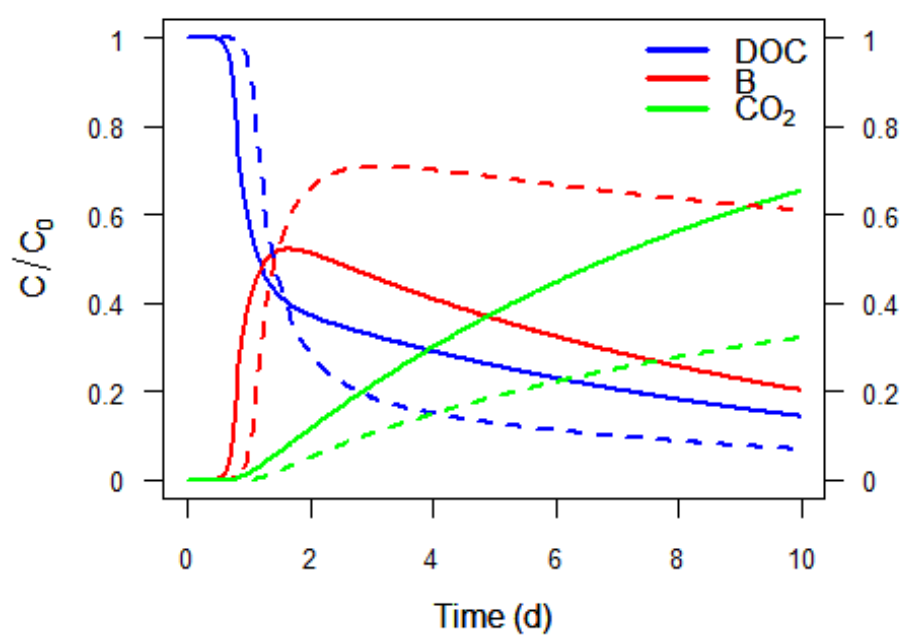

Figure 5: Effect of the factor physiology shown in the most homogeneous physical conditions, in terms of pore topology $\left(G_{4}\right)$, water saturation $\left(S_{w}=1\right)$ and bacterial distribution (Dispersed location). Plain and dashed lines are for the $P_{0}$ and $P_{1}$ physiology modalities, respectively.

Water saturation. We observed differential responses to water saturation. As the initial $B_{0}$ and $D O C_{0}$ values remained the same whatever the water con- 
tent, the overall DOC concentration varied as a function of the water volume. Water content decrease enhanced the rate of $\mathrm{C}$ mineralization in certain circumstances (figure 6a). However, saturation decrease did not always induce a gradual kinetics enhancement. When bacteria were distant from the substrate source (Bottom location), a slow linear DOC decrease could happen, indicating a severe consumption limitation, as for instance in the medium $G_{6}$ where $80 \%$ of the substrate was kept from degradation (figure $6 \mathrm{~b}$, dotted lines).

The divergence from an exponential behavior suggests that the global concentration of substrate did not control biodegradation/kinetics/alone. At the lowest water content, an increase in the tortuosity of the residual water phase possibly reduced the diffusion of substrate towards bacteria.

We observed in $G_{2}$ at $S_{w}=0.25$, an extreme case of such regulation mechanism, i.e. no bacterial growth (figure 6b, dashed-dotted lines). This cube presented a hydraulic discontinuity between the DOC source and the bottom of the narrow pore where bacteria were located (section 3.3, figure 4) at the lowest saturation index.

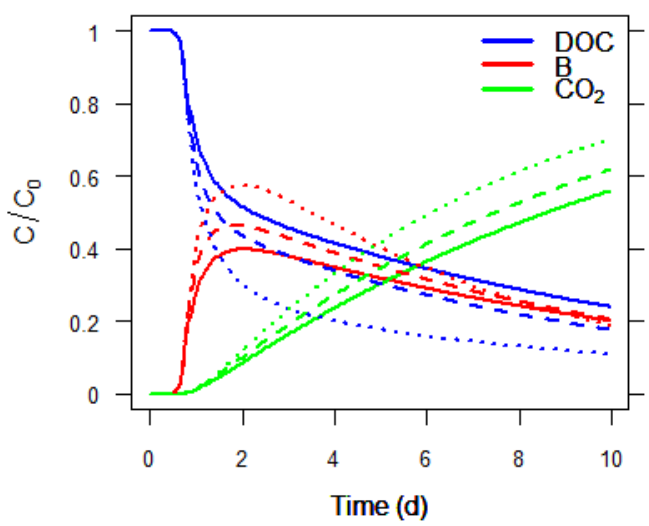

(a)

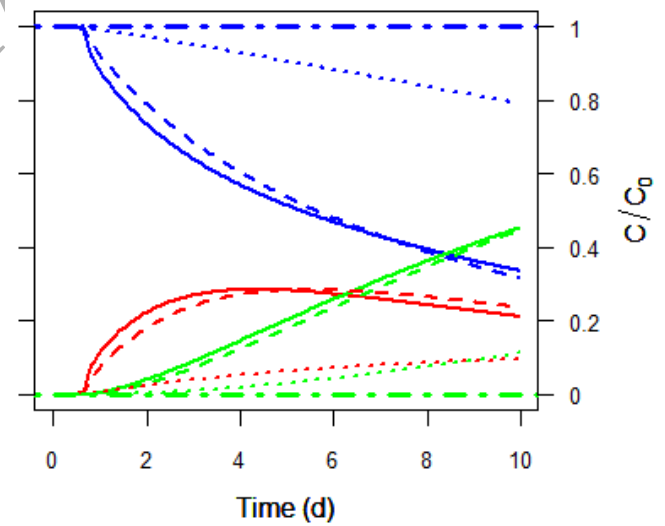

(b)

Figure 6: Effect of saturation factor crossed with location factor. The effect of saturation can be observed in each plot showing scenarios in Top (a) and Bottom location (b). Comparison of the two plots illustrates stimulation (a) or limitation (b) of kinetics that can be found for opposite bacterial distributions. Plain lines are for saturation $S_{w}=1$, dashed lines for $S_{w}=0.5$ and dotted lines for $S_{w}=0.25$. All kinetic curves are for medium $G_{6}$, except the dashed-dotted lines in (b) showing an extreme limitation of biodegradation in medium $G_{2}$ at $S_{w}=0.25$. 
Geometry. Each of the three sets of 18 scenarios in $G_{4}, G_{6}$ and $G_{2}$ displayed a high variability. $D O C$ values after ten days reached mean and coefficient of variation of $6 \%$ and $79 \%$ for $G_{4}, 25 \%$ and $86 \%$ for $G_{6}$ and $22 \%$ and $141 \%$ for $G_{2}$. The DOC consumption was always quick and intense in the most homogeneous cube $G_{4}$ (figure 7 ), regardless of the bacteria location or the water content, resulting in a low mean DOC value after ten days. By contrast, the highest CV value in $G_{2}(141 \%)$ reflected extremes in kinetics found for that cube, from severely restricted growth because of limited diffusion to quick and intense DOC uptake. Note that in $G_{2}$, where the highest overall concentration was found, the consumption of DOC was slow under complete saturation when the bacteria where located in the bottom of the cube (figure 7). The particular morphology of $G_{2}$ with a funnel-shaped pore ending with a long pore constriction generated a delay in diffusion of DOC towards the bacteria. The discontinuous water phase under low water content was therefore not the only constraint on biodegradation. In this case, high tortuosity due to pore morphology and the spatial disconnection between bacteria and DOC source were sufficient to reduce DOC uptake. Cumulated low overall concentration and high tortuosity effects were also responsible of the slow DOC decrease in cube $G_{6}$ under similar conditions (figure 7 ). 


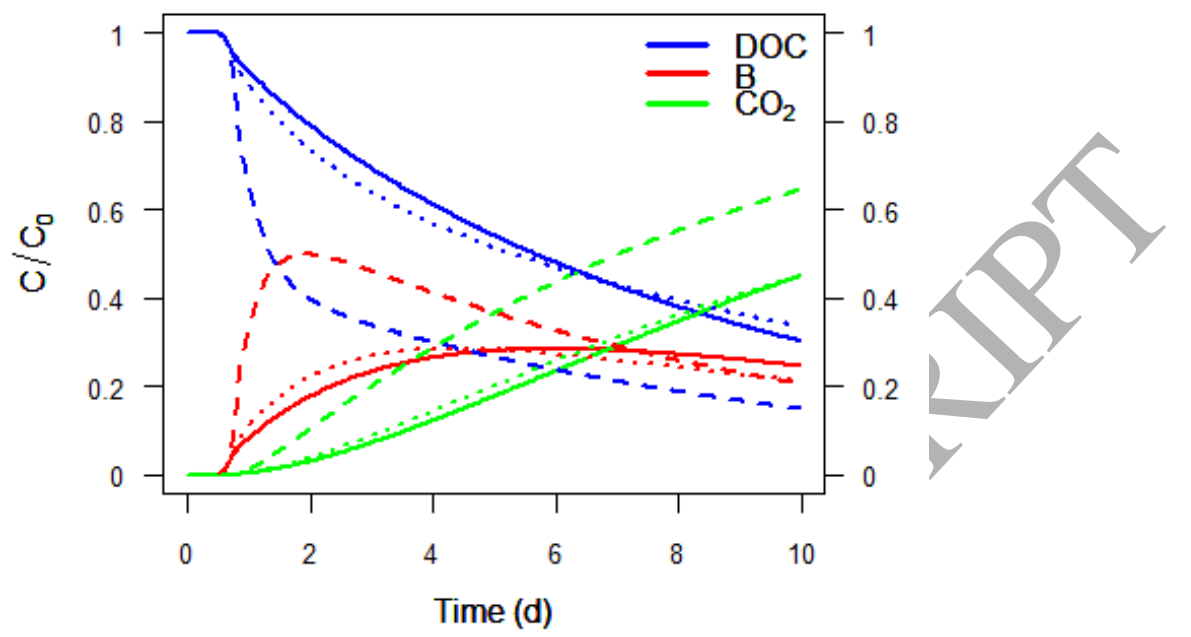

Figure 7: Effect of the geometry factor. The impact of morphological heterogeneity is shown for Bottom location under complete saturation $\left(S_{w}=1\right)$. Bacterial growth was exponential in the most homogeneous medium $G_{4}$ (dashed lines), while it was reduced in $G_{2}$ (plain lines) due to high diffusion constraint. The combination of moderate diffusion constraint and low overall substrate concentration resulted in similar growth reduction in $G_{6}$ (dotted lines).

Location. The degradation of DOC was noticeably lowered when bacteria were placed in the bottom of the cubes, as expected, because of the spatial disconnection between substrate input and bacteria (35\% of the initial DOC mass was left over after ten days, for Bottom location scenarios). The DOC uptake efficiency was similar in Dispersed and Top location modalities (10\% and $9 \%$ remaining $D O C$ respectively). Figure 8 a illustrates a case where DOC consumption was the quickest for the $L_{D}$ scenario. Bacteria located at the top were stimulated by the high surrounding substrate concentrations during early simulation times and therefore consumed all the DOC before the initial DOC gradient dissipated (figure 8a). However, in $L_{T}$ scenarios, when DOC diffused beyond the last bacterial spot (30 lu) it was no longer available to bacteria, until it began to diffuse in the opposite direction. The resulting biodegradation kinetics for Top location were slower than for the Dispersed location (figure 8b). It was found here that proximity to substrate and evenness of bacterial spots distribution affected the mineralization rates equally. 


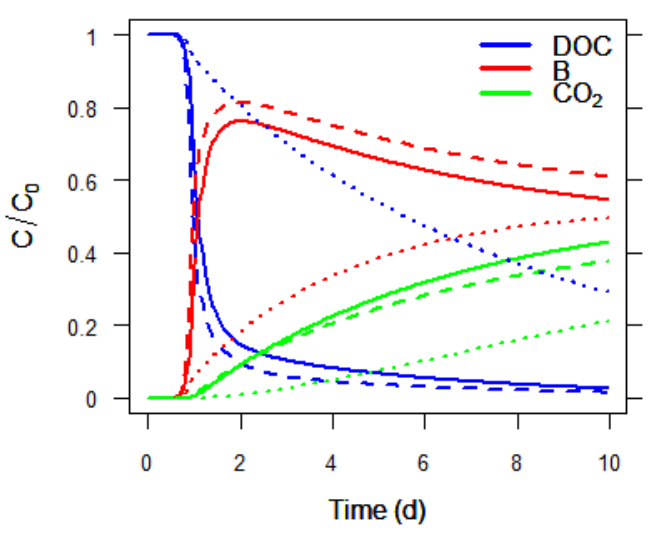

(a)

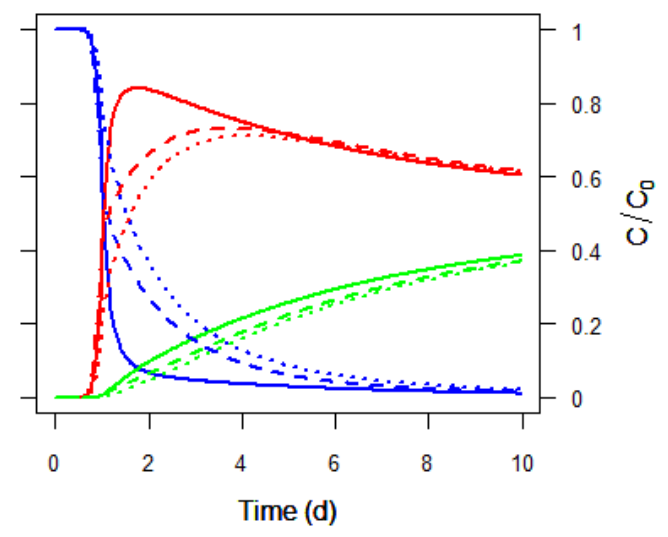

(b)

Figure 8: Effect of the location factor illustrated in two remarkable examples. Scenarios in medium $G_{6}$ at saturation $S_{w}=1$ are shown in (a), while scenarios in $G_{4}$ at $S_{w}=0.25$ are shown in (b). Either Dispersed (plain line) or Top (dashed line) distribution was found optimal for substrate consumption, while slowest kinetics always occurred for Bottom distribution (dotted line).

Local distribution of bacterial growth. Local variations of substrate availability induced contrasted bacterial development conditions depending on location modality. It could sometimes result in non-uniform distributions of biomass between the ten initialized sites. For instance, in $G_{2}$ and with bacteria distributed in bottom and under complete saturation, a disparity in the bacterial development appeared and settled through the ten days (figure $9 a)$. Indeed, in the narrow long pore of cube $G_{2}$, there was only one diffusion pathway meaning that access to substrate differed depending on spots depth. Bacterial biomass was therefore distributed as a gradient along the diffusion pathway, so that the uppermost bacterial sites deprived the deeper ones of DOC. This can be viewed as a kind of competition, independent of the organisms' capacities and only based on their spatial arrangement. This gradient did not appear for similar scenarios in the other two cubes (figure $9 \mathrm{~b}$ ), suggesting that diffusion pathways were more isotropic, resulting in a more equal access to DOC. 


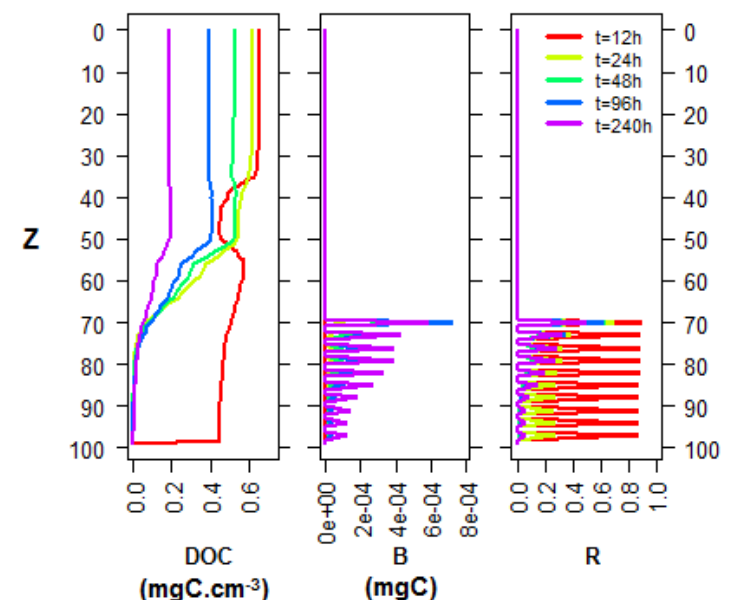

(a)

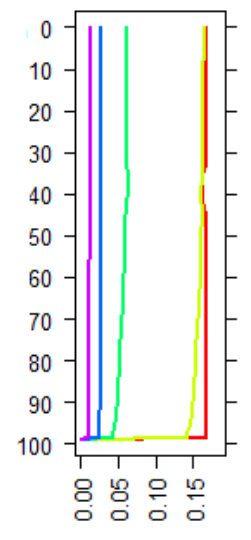

DOC $\left(\mathrm{mgC} . \mathrm{cm}^{-3}\right)$

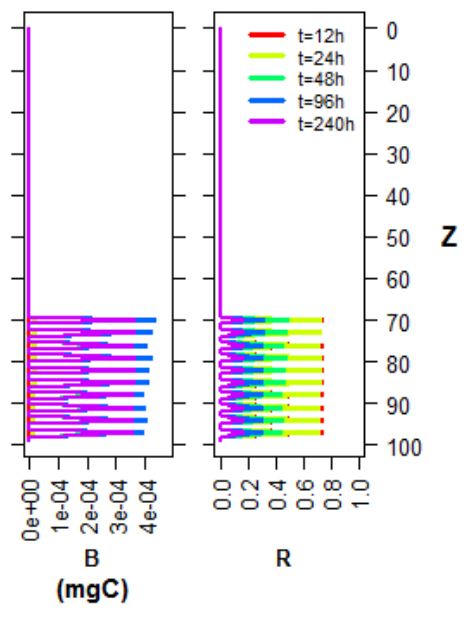

(b)

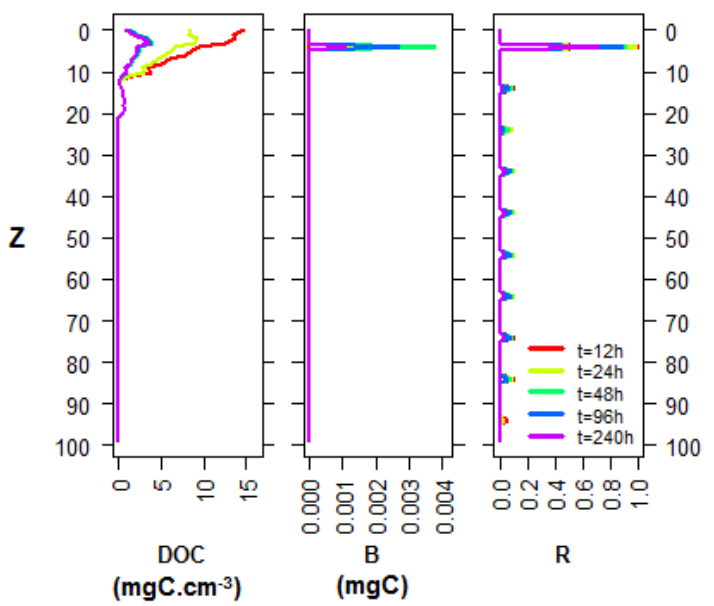

(c)

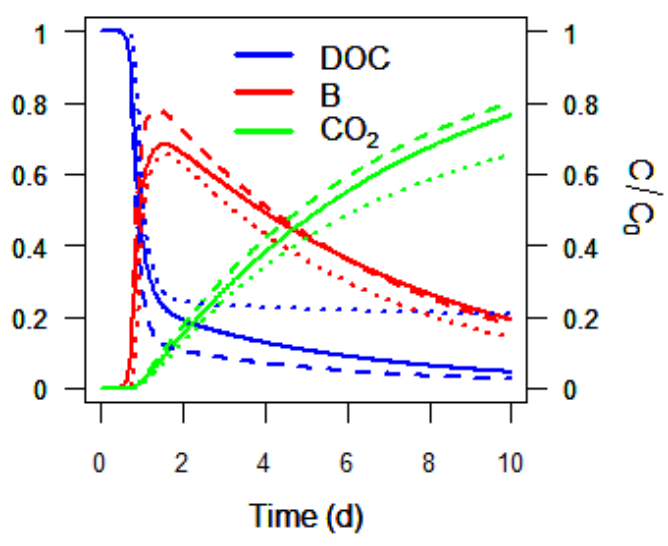

(d)

Figure 9: 1D profiles of DOC concentration, biomass and activity of bacteria at different time steps in three different scenarios: $G_{2}, L_{B}, S w=1$ and $P_{1}$ in (a), $G_{4}$, $L_{B}, S w=1, P_{1}$ in (b), and $G_{2}, L_{D}, S_{w}=0.25, P_{1}$ in (c). The global kinetics of DOC biodegradation of the latter scenario in (c) was compared in (d) to similar cases at higher saturation levels (plain lines are for $S_{w}=1$, dashed lines for $S_{w}=0.5$ and dotted lines for $\left.S_{w}=0.25\right)$. Variations in substrate concentrations influenced the distribution of mass and activity between bacterial spots $(\mathrm{a}, \mathrm{b})$. The optimal activity in only one spot supplied with substrate (c) partly offset the inactivation of isolated ones, as can be seen on global kinetics (d). 
Once again in cube $G_{2}$ at the lowest water content, the isolation of bacterial spots from the substrate induced by hydraulic disconnection revealed a peculiarity of the system. In the Dispersed location scenario, only one bacterial spot was hydraulically connected to the substrate source. This bacterial spot was therefore not subjected to any competitive pressure for the resource (figure 9c) and was almost as efficient in taking up DOC as all bacterial spots in similar scenarios at higher water contents $\left(S_{w}=1, S_{w}=0.5\right)$ and released similar amounts of $\mathrm{CO}_{2}$. The physiological state $R$ - when it was allowed to vary (scenarios $P_{1}$ ) - quickly increased to 1 and stayed close to that value throughout the ten days (figure 9c) so that activity of the bacterial spot was optimal. It resulted thus in an intense respiration and consequent biomass decline (figure 9d).

Summary. These results showed two antagonistic effects caused by the meso and macropores shape on the biodegradation of DOC. The limitation of biodegradation by diffusion became dominant when a high tortuosity was combined with a large spatial - or even hydraulic - disconnection between substrate and decomposers (Bottom location). The increase of tortuosity induced a delay in the diffusion of DOC in the case of a complex pore topology (cube $\left.G_{2}\right)$ and/or low saturation $\left(S_{u}=0.25\right)$. The limitation by diffusion was counterbalanced by a stimulation of the bacterial activity through local increases in the concentration of DOC by both decrease of saturation and decrease of porosity in case the pore topology was not too heterogeneous $\left(G_{4}\right)$ and substrate source and bacteria were not too distant (Top and Dispersed locations). Finally, in some cases, the activation of the physiological state $R\left(P_{1}\right)$ enhanced the overall substrate uptake efficiency in the most homogeneous conditions. Local variations of bacterial activity were also sometimes shown to offset the impact of diffusion limitation .

\subsection{Global sensitivity analysis results}

Figure 10 shows the results of the variance analysis for each global variable (DOC, B and $\mathrm{CO}_{2}$ ) after three and ten days of simulation. After three days, the total variance of the values of every variable was mainly explained by the location (41 to $50 \%$ of the total variance) and to a lesser extent by the geometry of the pore network (explaining $13 \%$ of the total variance for $D O C$ and $19 \%$ for $B$ ) and the interaction between the two ( $G: L$ explaining 21, 18 and $17 \%$ of the total variance for $D O C, B$ and $C_{2}$ respectively). The 
impact of bacterial physiology was also significant for $\mathrm{CO}_{2}$ (explaining $13 \%$ of the total variance).
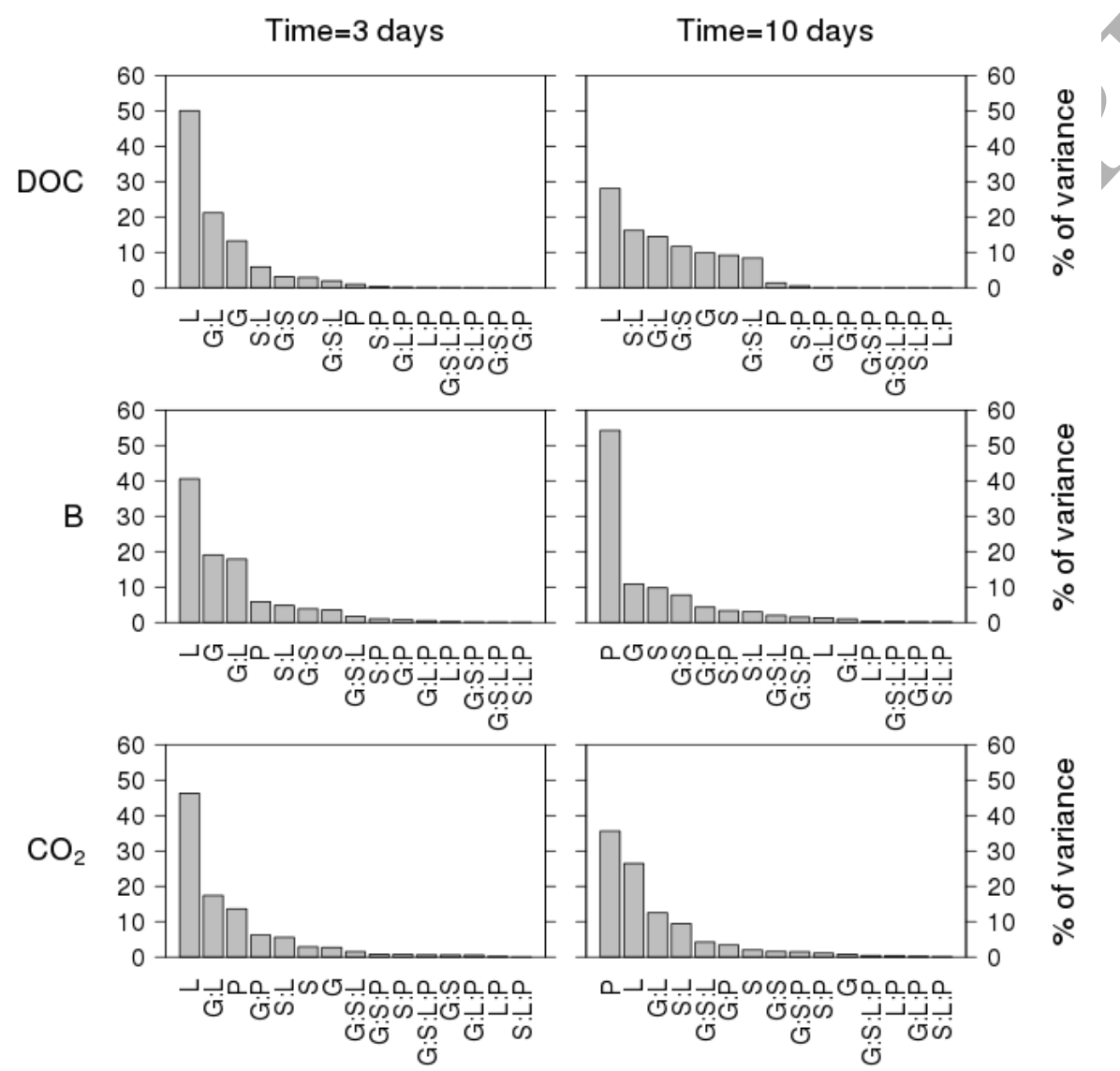

Figure 10: Contribution parts of the total variance in the values of $D O C, B$ and $\mathrm{CO}_{2}$ attributed to the factors $G, S, L, P$ and their interactions, expressed as percentage. ":" denotes the interaction.

After ten days, variance partitioning shifted differently for the three output variables. Drastic changes appeared for $B$, for which physiology dominated, explaining $54 \%$ of total variance on its own, while the location effect was negligible ( $1 \%$ of the total variance). However, location remained a major factor for $D O C$ ( $1^{\text {st }}$ rank, explaining $28 \%$ of the total variance) and $\mathrm{CO}_{2}$ ( $2^{\text {nd }}$ rank, explaining $26 \%$ of the total variance), though its contribution to 
the total variability was lower than after three days. Half of the total variance $(51 \%)$ was explained by interactions between physical factors $(S: L, G: L$, $G: S$ and $G: S: L)$. Physiology had a minor impact on $D O C$, either alone (1\%) or in interaction (less than $1 \%$ ). $\mathrm{CO}_{2}$, as an integrative variable, displayed intermediate results between $D O C$ and $B$ with physiology $(35 \%)$ and location $(26 \%)$ having the strongest influence. The total contribution of the interacting physical factors ( $G: S, G: L, S: L$ and $G: S: L)$ explained $28 \%$ of the total variance of $\mathrm{CO}_{2}$.

The differences observed between three days and ten days of incubation resulted from cumulative effects during the biodegradation process. For instance, after three days, the physical factors, and in particular the location of bacteria relative to substrate, were predominant in initiating bacterial growth while after ten days, the partition of $\mathrm{C}$ in either $\mathrm{CO}_{2}$ or $\mathrm{B}$ pools was mainly the results of the physiology.

The complexity of the bacterial responses to the same resource input made it difficult to establish a hierarchy of the contribution of the different factors to biodegradation (section 5.2). The analysis of variance indicated a significant contribution of the interactions between the physical factors. In particular, it confirmed that the interactions between the different physical factors better explained the variability of biodegradation than some of these factors alone, as was observed in section 5.2. For instance, $G: S$ or $S: L$ contributed more to $D O C$ values variability than $S$ alone. Interactions between saturation and the other physical factors explained the antagonistic effects of hydration status on biodegradation, as it has been already raised above.

By contrast, the interactions between $P$ and other factors had a rather weak effect, whatever the variable, but especially for $D O C$. It suggests that the effect of physical factors on DOC biodegradation was independent to physiology in these scenarios. Indeed, the same trends could be found when comparing scenarios with similar physical conditions but different physiology modalities.

Finally, it was pointed out that $D O C, B$ and $\mathrm{CO}_{2}$ obtained contrasted results, It suggests that following the $\mathrm{CO}_{2}$ global value as an indicator for the fate of organic substrate in soils, as it is frequently done, could actually be insufficient.

Variability associated to local bacterial positions. Highest CV were obtained in $G_{2}$ for $T o p(46 \%)$ and Dispersed $(74 \%)$ location modalities, while no variability appeared for Bottom location $\left(\mathrm{CV}=5 \times 10^{-6}\right)$. A lowest variation 
range was found in media $G_{4}$ and $G_{6}$ : from $4 \%\left(G_{4}, L_{B}\right)$ to $26 \%\left(G_{6}, L_{D}\right)$.

At $S_{w}=0.25$, the diffusion pathways were very heterogeneous. Thus, changes in $X$ and $Y$ coordinates modified the local substrate availability for each bacterial spot and thus its development. In $G_{2}$ for Dispersed and Top location modalities, a few bacterial sites were always hydraulically connected to the DOC input and could therefore take part to the degradation. The highest variability in that cases results from the number of connected bacterial sites that varied between random selections (figure not shown) and thus occasioned marked differences in global kinetics.

The variability found here suggested that the quantification of factors impact presented before depends on our arbitrary selections of bacterial sites positions, but confirmed the weight of the interaction $G: L$ on DOC degradation highlighted by the global sensitivity analysis.

\section{Discussion and conclusion}

The use of a pore-scale model, coupling Lattice-Boltzmann and compartmental biological models, to simulate biodegradation by taking into account pore topology appeared here as a promising tool for challenging hypotheses about the role of heterogeneous soil microenvironments on biodegradation processes. The transport of a non-sorbing soluble substrate and its utilization by bacteria could be simulated simultaneously in relatively sophisticated representations of meso- and macropore space, as compared to the simplistic media found in other microbial dynamics models integrating spatial heterogeneity like [25-30].

For the first time, we quantified the effect of heterogeneous distribution of some meaningful abiotic parameters in meso- and macropores, on the regulation of biodegradation using a complete factorial design. A global sensitivity analysis was applied on the results of the 54 generated scenarios. The total variance could be decomposed into contribution parts of four tested factors - pore space geometry, water content, substrate-decomposers spatial arrangement, bacterial physiology - and their interactions. The results of the global sensitivity analysis emphasized the role of the physical heterogeneity in our scenarios. It revealed the influence of the interactions between the three physical factors, as they explained a significant part of the variability of the substrate concentration.

In our scenarios, the prevailing abiotic control played through diffusion, as it was the only physical process that determined substrate accessibility to 
bacteria. Antagonistic effects could be identified due to the contrasted water saturation conditions combined with decomposers spatialization, highlighting once again the role of interactions between physical factors. On the one hand, we found that prolonged access to plentiful substrate could locally enhance bacterial degrading activity. On the other hand, reduced diffusion rates were sometimes found to slow down or even prevent biodegradation when discontinuities in the water phase blocked substrate propagation. Don et al., disregarding microscale heterogeneity and transport processes, interpreted such stimulation as a consequence of the increased probability of encounter between substrates and microorganisms [75]. Moderate diffusion limitation has already been suggested $[9,45,76]$ or shown experimentally $[7,77]$ and is likely to be frequent in natural conditions, whereas the extreme limitation case we found has to be regarded with caution. Indeed, the disconnection of water phase resulted from the coarse discretization of the grid and was thus a consequence of experimental and modeling setting (see section 3.3).

However, if some submillimeter scale effects simulated here are relevant for soils, diffusion control probably does not exert in the same extent in soils. First it is expected that the diffusion conditions will strongly differ between the real samples and their discretized images, because a significant part of the porosity remained unresolved at the submillimeter scale. A finer reproduction of soil pore space would i) considerably increase the porosity of the images as we represented only $14 \%$ of the total soil porosity, ii) include tortuous diffusion pathways in micropores and iii) provide more realistic representation of the water phase through a better resolution of thin water films ensuring a reduced but continuous solute transport. This would tend to induce increased and persisting concentration gradients and may thus amplify the contrasts between bacteria, depending on their local position. Second, introducing mechanisms allowing for bacteria motion would probably counterbalance partly our conclusions that diffusion played a major control on the biodegradation kinetics.

Despite our scenarios imperfectly depicted the complex processes found in real soils, the effects attributed to physical heterogeneity at the meso and macropore scale that were revealed here can be compared to results obtained with simplified experimental systems. Our scenarios generated a high but still realistic variability in biodegradation response. The coefficient of variation of $44 \%$ found here for 10 -days $\mathrm{CO}_{2}$ emissions was close to values obtained in experimental studies exploring the effect of spatial heterogeneity on the mineralization of soluble substrates at the millimeter scale: Monard 
et al. obtained slightly lower CV for glucose (14-22\%) [8], while CV values ranging from 25 to $160 \%$ have been found for the soluble pesticide 2,4-D $[3,4,8]$.

The spatial arrangement of substrate and decomposers was found to have the greatest impact of substrate bioavailability, inducing in our case high variation in DOC consumption. This was in agreement with Chenu et al. who showed that the accessibility of soluble organic carbon to the soil decomposers can be either limited or enhanced by the existence of heterogeneous spatial distributions of microbial communities in the soil porosity [78].

Bioavailability of substrate was also investigated by modulating substratedecomposers spatialization in $[7,58]$, but at a larger scale $(\mathrm{mm} /$ to $\mathrm{cm})$. The degradation of 2,4-D drastically decreased from $50 \%$ in the case of a homogeneous substrate and biomass repartition to $0.3 \%$ when separating substrate and biomass by $2 \mathrm{~cm}$ [58]. Dechesne et al. placed artificial bacterial hotspots (i.e. alginate beads) separated by few millimeters in sand microcosms [7]. They found an increased biodegradation efficiency when they inoculated bacteria on nine positions as compared to a single central spot of the same initial mass. We also found that a dispersed distribution of bacteria could sometimes be a better strategy than gathering the spots even near the substrate source. In other studies, the importance of spatial disconnection was investigated indirectly by studying biodegradation in different pore size classes. Substrates and/or bacteria were experimentally placed in different pore size classes by manipulating the water potential and consequently the equivalent radius of water-filled pores according to Young-Laplace law. In [79] substrate mineralization was contrasted among pore size classes while in $[80,81]$, bacteria or substrate placement had little effect.

The combined effect of substrate location and water potential was illustrated by experimental works based on the incubation of soluble substrates, such as glucose and 2,4-D [8], and benzoate [7]. Dechesne et al. found cumulative effects of the water potential and the biomass distribution, with high water potential and dispersed distribution both stimulating the mineralization of benzoate [7]. No clear interaction between the two factors appeared, maybe because of the homogeneous initial distribution of the substrate. By contrast, the distribution of bacteria and substrate was found to affect mineralization differently depending on the water content in [31]. In the model used by the authors, organic matter and bacteria could be in air-fille d pores and have no influence on the intensity or rate of mineralization, meaning that there were changes in the effective biomass and organic matter as the 
water content changed. In our model, this was not the case as the bacteria and DOC always remained in the water phase. The different location effects observed in our results and in their work are therefore not strictly comparable.

Although biology was simplified and a coarse resolution was chosen in the present work, the diversity of the biological responses in these simulation scenarios where physical heterogeneity was explicitly described at the mesoand macropore scale, mirrored some variability found in experimental data. Removing these simplifying assumptions can be progressively done in the modeling tool provided here. The approach appears thus promising to further investigate the role of soil structure in SOM decomposition in more realistic pictures of soils.

\section{Acknowledgments}

This work benefited from the French ANR project ANR-09-SYSCOMM MEPSOM. We acknowledge Veolia Environment group for financial support of the QUALIAGRO field site where soil were sampled. The soil samples were scanned in SIMBIOS Centre (University of Abertay, Dundee, Scotland). We would like to thank Gérald Debenest and Isabelle Cousin for fruitful discussions.

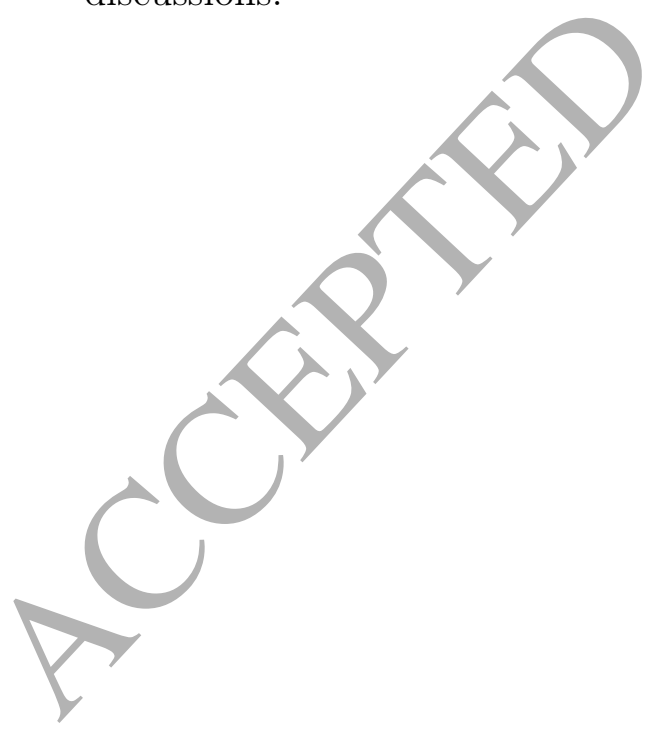


AppendixA. DOC biodegradation kinetics of the 54 scenarios

L: Dispersed
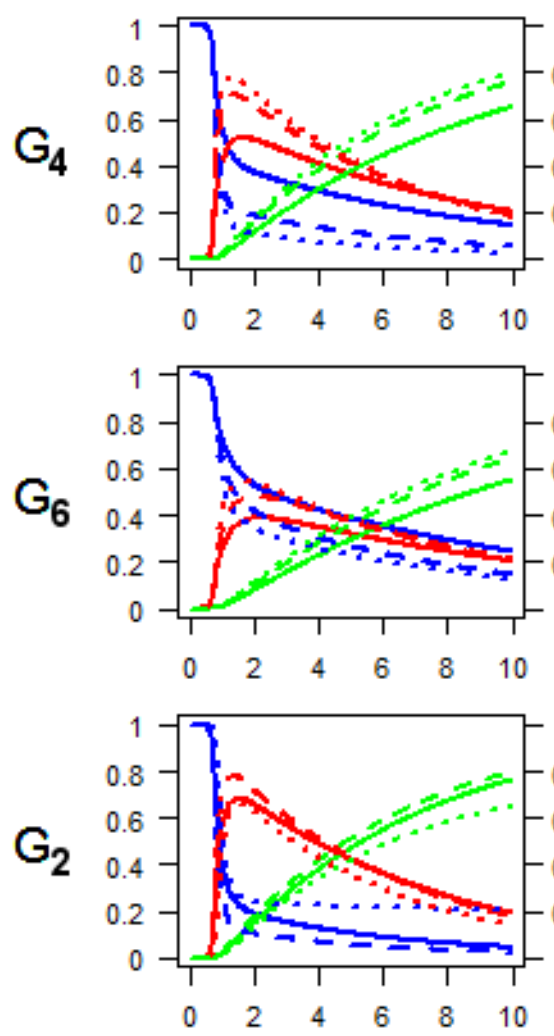

Time (days)
L: Top
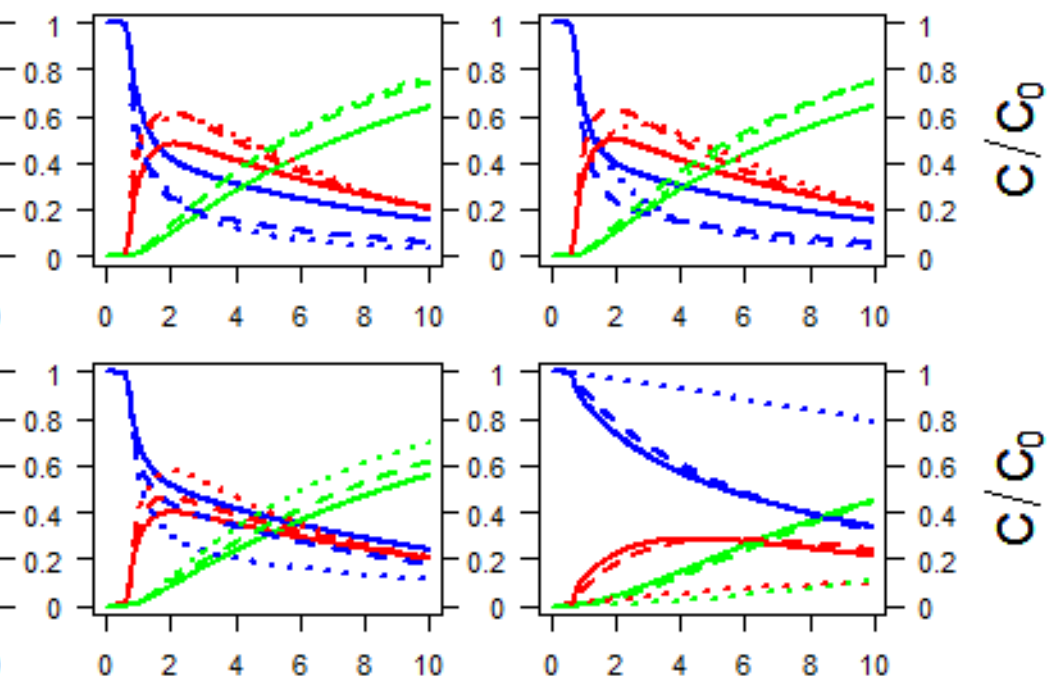

L: Bottom
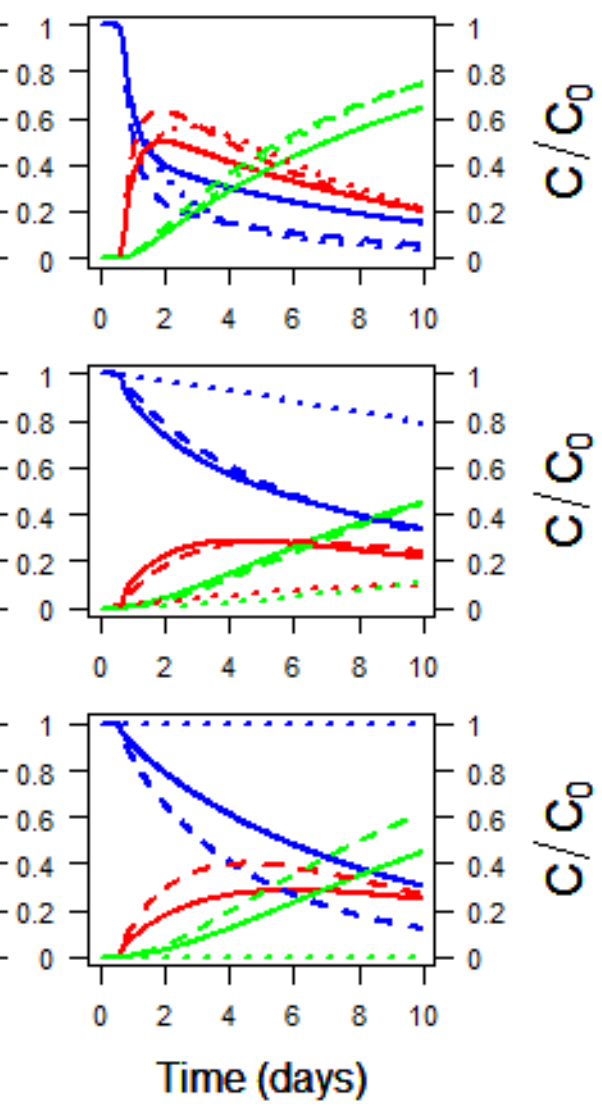

(a) Physiology $P_{0}$

Figure A.11: DOC biodegradation kinetics of all scenarios displayed on separate pages for different physiology modalities $\left(P_{0}\right.$ in (a) and $P_{1}$ in (b)). In each plot, inserts are ordered by row for geometry and by column for location factor. Inside of each insert, the three saturation levels are represented by different line styles $\left(S_{w}=1\right.$ in plain, $S_{0.5}$ in dashed and $S_{w}=0.25$ in dotted lines). $D O C, B$ and $\mathrm{CO}_{2}$ are shown in blue, red and green respectively. 

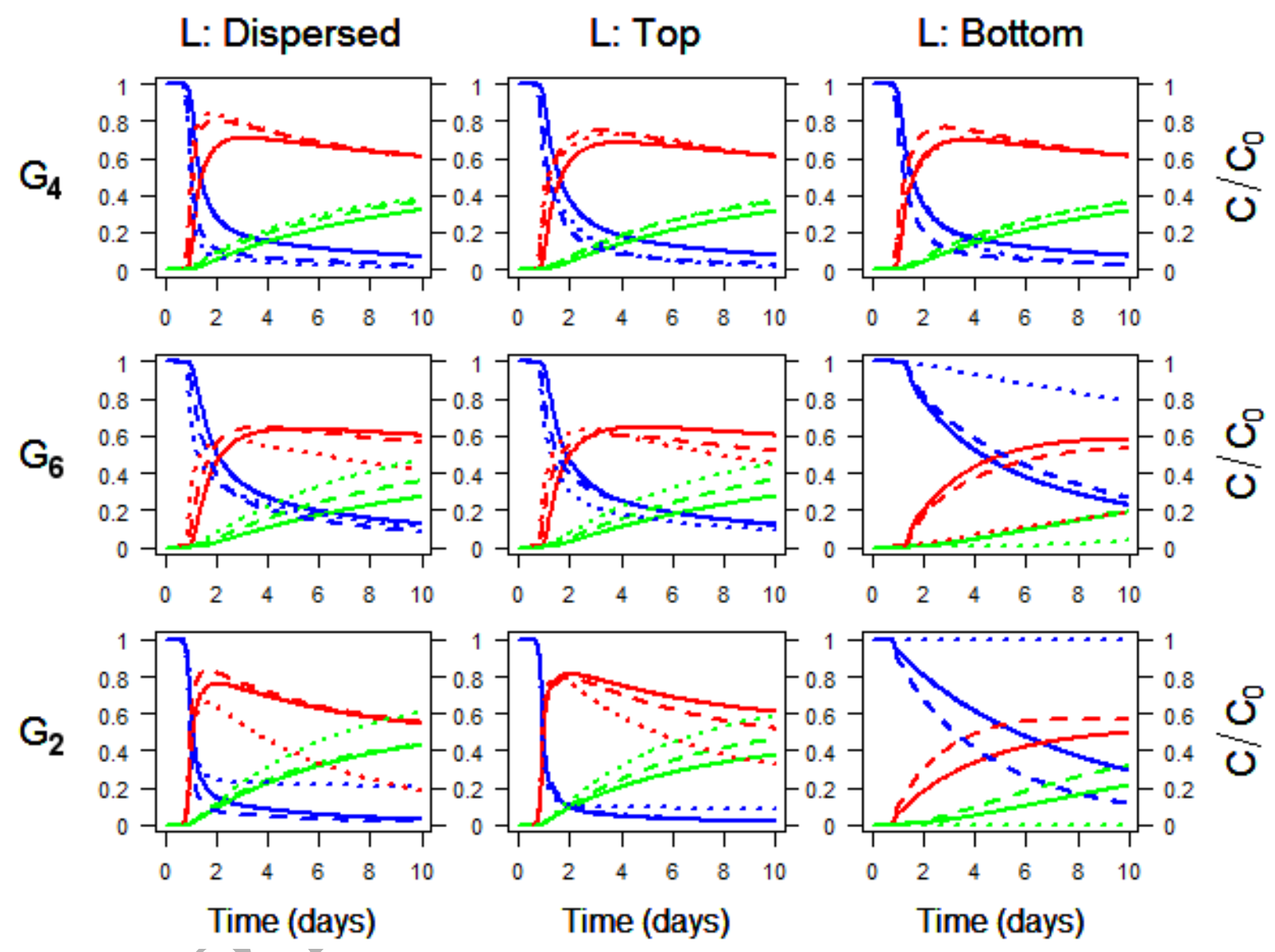

(b) Physiology $P_{1}$

Figure A.11: DOC biodegradation kinetics of the 54 scenarios. Scenarios of different physiology are displayed on separate pages $\left(P_{0}\right.$ in $(\mathrm{a})$ and $P_{1}$ in (b)). In each plot, inserts are ordered by row for geometry and by column for location factor. Inside of each insert, the three saturation levels are represented by different line styles $\left(S_{w}=1\right.$ in plain, $S_{w}=0.5$ in dashed and $S_{w}=0.25$ in dotted lines). DOC, B and $\mathrm{CO}_{2}$ are shown in blue, red and green respectively. 
[1] P. Bellamy, P. Loveland, R. Bradley, R. Lark, K. G.J.D., Carbon losses from all soils across england and wales 1978-2003, Nature 437 (2005) $245-248$.

[2] N. Nunan, K. Wu, I. Young, J. Crawford, K. Ritz, In situ spatial patterns of soil bacterial populations, mapped at multiple scales, in an arable soil, Microbial Ecology 44 (4) (2002) 296 305. doi:http://dx.doi.org/10.1007/s00248-002-2021-0.

[3] L. Vieublé-Gonod, C. Chenu, G. Soulas, Spatial variability of 2, 4dichlorophenoxyacetic acid (2, 4-d) mineralisation potential at a millimetre scale in soil, Soil Biology and Biochemistry 35 (3) (2003) 373-382. doi:http://dx.doi.org/10.1016/S0038-0717(02)00287-0.

[4] L. Vieublé Gonod, J. Chadoeuf, C. Chenu, Spatial distribution of microbial 2, 4-dichlorophenoxy acetic acid mineralization from field to microhabitat scales, Soil Science Society of America Journal 70 (1) (2006) 64-71. doi:http://dx.doi.org/10.2136/sssaj2004.0034.

[5] X. Raynaud, N. Nunan, Spatial Ecology of Bacteria at the Microscale in Soil, PLoS ONE 9 (1) (2014) e87217. doi:http://dx.doi.org/10.1371/journal.pone.0087217.

[6] A. J. Smucker, E.-J. Park, J. Dorner, R. Horn, Soil micropore development and contributions to soluble carbon transport within macroaggregates, Vadose Zone Journal 6 (2) (2007) 282-290. doi:http://dx.doi.org/10.2136/vzj2007.0031.

[7] A. Dechesne, G. Wang, G. Gülez, D. Or, B. F. Smets, Hydrationcontrolled bacterial motility and dispersal on surfaces, Proceedings of the National Academy of Sciences 107 (32) (2010) 14369-14372. doi:http://dx.doi.org/10.1073/pnas.1008392107.

[8] C. Monard, C. Mchergui, N. Nunan, F. Martin-Laurent, L. VieubléGonod, Impact of soil matric potential on the fine-scale spatial distribution and activity of specific microbial degrader communities, FEMS Microbiology Ecology 81 (3) (2012) 673-683. doi:http://dx.doi.org/10.1111/j.1574-6941.2012.01398.x.

[9] D. Or, B. Smets, J. Wraith, A. Dechesne, S. Friedman, Physical constraints affecting bacterial habitats and activity in unsaturated porous 
media - a review, Advances in Water Resources 30 (6-7) (2007) 1505 1527. doi:http://dx.doi.org/10.1016/j.advwatres.2006.05.025.

[10] M. Vos, A. B. Wolf, S. J. Jennings, G. A. Kowalchuk, Microscale determinants of bacterial diversity in soil, FEMS Microbiology Reviewsdoi:http://dx.doi.org/10.1111/1574-6976.12023.

[11] J. W. Barton, R. M. Ford, Determination of effective transport coefficients for bacterial migration in sand columns. Applied and Environmental Microbiology 61 (9) (1995) 3329-3335. doi:http://dx.doi.org/10.1016/0009-2509(96)00302-8.

[12] M. Van Loosdrecht, J. Lyklema, W. Norde, A. Zehnder, Influence of interfaces on microbial activity., Microbiological Reviews 54 (1) (1990) 75-87. doi:http://dx.doi.org/10.1016/j.geoderma.2014.07.029.

[13] G. Pandey, R. K. Jain, Bacterial chemotaxis toward environmental pollutants: role in bioremediation, Applied and Environmental Microbiology 68 (12) (2002) 5789-5795. doi:http://dx.doi.org/10.1128/AEM.68.12.5789-5795.2002.

[14] S. Kohlmeier, T. H. Smits, R. M. Ford, C. Keel, H. Harms, L. Y. Wick, Taking the fungal highway: mobilization of pollutant-degrading bacteria by fungi, Environmental Science \& Technology 39 (12) (2005) 46404646. doi:http://dx.doi.org/10.1021/es047979z.

[15] A. O'Donnell, I. Young, S. Rushton, M. Shirley, J. Crawford, Visualization, modelling and prediction in soil microbiology, Nature Reviews - Microbiology 5 (2007) 689 - 699. doi:http: //dx,doi.org/10.1038/nrmicro1714.

[16] I. M. Young, J. W. Crawford, Interactions and self-organization in the soil-microbe complex, Science 304 (5677) (2004) 1634-1637. doi:http://dx.doi.org/10.1126/science.1097394.

[17] B. Ball, Soil structure and greenhouse gas emissions: a synthesis of 20 years of experimentation, European Journal of Soil Science 64 (2013) 357-373. doi:http://dx.doi.org/10.1111/ejss.12013.

[18] E. A. Davidson, S. Samanta, S. S. Caramori, K. Savage, The Dual Arrhenius and Michaelis-Menten kinetics model for decomposition of 
soil organic matter at hourly to seasonal time scales, Global Change Biology 18 (1) (2012) 371-384. doi:http://dx.doi.org/10.1111/j.13652486.2011.02546.x.

[19] F. E. Moyano, S. Manzoni, C. Chenu, Responses of soil heterotrophic respiration to moisture availability: An exploration of processes and models, Soil Biology and Biochemistry 59 (2013) 72-85. doi:http://dx.doi.org/10.1016/j.soilbio.2013.01.002.

[20] P. C. Baveye, D. Rangel, A. R. Jacobson, M. Laba, C. Darnault, W. Otten, R. Radulovich, F. A. Camargo, From dust bowl to dust bowl: soils are still very much a frontier of science, Soil Science Society of America Journal 75 (6) (2011) 2037-2048. doi:http://dx.doi.org/10.2136/sssaj2011.0145.

[21] P. Falloon, C. D. Jones, M. Ades, K. Paul, Direct soil moisture controls of future global soil carbon changes: An important source of uncertainty, Global Biogeochemical Cycles 25 (3). doi:http://dx.doi.org/10.1029/2010GB003938.

[22] S. Sleutel, V. Cnudde, B. Masschaele, J. Vlassenbroek, M. Dierick, L. Van Hoorebeke, P. Jacobs, S. De Neve, Comparison of different nano- and micro-focus x-ray computed tomography setups for the visualization of the soil microstructure and soil organic matter, Computers and Geosciences 34 (8) (2008) 931-938. doi:http://dx.doi.org/10.1016/j.cageo.2007.10.006.

[23] V. Cnudde, B. Masschaele, M. Dierick, J. Vlassenbroeck, L. V. Hoorebeke, P. Jacobs, Recent progress in X-ray CT as a geosciences tool, Applied Geochemistry 21 (5) (2006) 826-832. døi:http://dx.doi.org/10.1016/j.apgeochem.2006.02.010.

[24] H.-J. Vogel, J. Tölke, V. Schulz, M. Krafczyk, K. Roth, Comparison of a lattice-Boltzmann model, a full-morphology model, and a pore network model for determining capillary pressuresaturation relationships, Vadose Zone Journal 4 (2) (2005) 380-388. doi:http://dx.doi.org/10.2136/vzj2004.0114.

[25] C. Knutson, C. Werth, A. Valocchi, Pore-scale simulation of biomass growth along the transverse mixing zone of a model two-dimensional 
porous medium, Water Resources Research 41 (7) (2005) W07007. doi:http://dx.doi.org/10.1029/2004WR003459.

[26] D. Masse, C. Cambier, A. Brauman, S. Sall, K. Assigbetse, J.-L. Chotte, Mior: an individual-based model for simulating the spatial patterns of soil organic matter microbial decomposition, European Journal of Soil Science 58 (5) (2007) 1127-1135. doi:http://dx.doi.org/10.1111/j.13652389.2007.00900.x.

[27] T. Long, D. Or, Dynamics of microbial growth and coexistence on variably saturated rough surfaces, Microbial Ecology 58 (2) (2009) 262-275. doi:http://dx.doi.org/10.1007/s00248-009-9510-3

[28] H. Resat, V. Bailey, L. A. McCue, A. Konopka, Modeling microbial dynamics in heterogeneous environments: growth on soil carbon sources, Microbial Ecology 63 (4) (2012) 883-897. doi:http://dx.doi.org/10.1007/s00248-011-9965-x.

[29] H. J. Folse III, S. D. Allison, Cooperation, competition, and coalitions in enzyme-producing microbes: social evolution and nutrient depolymerization rates, Frontiers in Microbiology 3 . doi:http://dx.doi.org/10.3389/fmicb.2012.00338.

[30] M. Gharasoo, F. Centler, P. Regnier, H. Harms, M. Thullner, A reactive transport modeling approach to simulate biogeochemical processes in pore structures with pore-scale heterogeneities, Environmental Modelling \& Software 30 (2012) 102-114. doi:http://dx.doi.org/10.1016/j.envsoft.2011.10.010.

[31] O. Monga, M. Bousso, P. Garnier, V. Pot, 3D geometric structures and biological activity: Application to microbial soil organic matter decomposition in pore space, Ecological Modelling 216 (3-4) (2008) 291302. doi:http://dx.doi.org/10.1016/j.ecolmodel.2008.04.015.

[32] R. E. Falconer, A. N. Houston, W. Otten, P. C. Baveye, Emergent behavior of soil fungal dynamics: Influence of soil architecture and water distribution, Soil Science 177 (2) (2012) 111-119. doi:http://dx.doi.org/10.1097/SS.0b013e318241133a.

[33] J. Chau, D. Or, M. Sukop, Simulation of gaseous diffusion in partially saturated porous media under variable gravity with 
lattice boltzmann methods, Water Resources Research 41 (8). doi:http://dx.doi.org/10.1029/2004WR003821.

[34] A. Genty, V. Pot, Numerical simulation of 3D liquid-gas distribution in porous media by a two-phase TRT lattice Boltzmann method, Transport in Porous Media 96 (2) (2013) 271-294. doi:http://dx.doi.org/10.1007/s11242-012-0087-9.

[35] I. Ginzburg, Equilibrium-type and link-type lattice Boltzmann models for generic advection and anisotropic-dispersion equation, Advances in Water Resources 28 (11) (2005), 1171-1195. doi:http://dx.doi.org/10.1016/j.advwatres.2005.03.004.

[36] I. Ginzburg, F. Verhaeghe, D. d'Humières, Two-Relaxation-Time lattice Boltzmann scheme: About parametrization, yelocity, pressure and mixed boundary conditions, Communications in Computational Physics 3 (2) (2008) 427-478.

[37] X. Shan, H. Chen, Lattice boltzmann model for simulating flows with multiple phases and components, Physical Review E 47 (3) (1993) 1815. doi:http://dx.doi.org/10.1103/PhysRevE.47.1815.

[38] V. Pot, H. Hammou, N. Elyeznasni, I. Ginzburg, Role of soil heterogeneities onto pesticide fate: a pore-scale study with lattice boltzmann, in: 1st International Conference and Exploratory Workshop on Soil Architecture and Physico-Chemical Functions, "CESAR" proceedings Aarhus University, Research Centre Foulum (DNK), 2010, p. 4.

[39] S. Hansen, M. Shaffer, L. Ma (Eds.), Modeling Carbon and Nitrogen Dynamics for Soil Management, CRC Press, 2001. doi:http: / dx.doi.org/10.1201/9781420032635.

[40] D. H.)Jennings, G. Lysek, et al., Fungal biology: understanding the fungal lifestyle., Bios Scientific Publishers Ltd, 1996.

[41] J. Lobry, J. Flandrois, G. Carret, A. Pave, Monod's bacterial growth model revisited, Bulletin of Mathematical Biology 54 (1) (1992) 117122. doi:http://dx.doi.org/10.1016/S0092-8240(05)80179-X. 
[42] O. Monga, P. Garnier, V. Pot, E. Coucheney, N. Nunan, W. Otten, C. Chenu, Simulating microbial degradation of organic matter in a simple porous system using the 3 -d diffusion-based model mosaic, Biogeosciences 11 (8) (2014) 2201-2209. doi:http://dx.doi.org/10.5194/bg-112201-2014.

[43] G. Wang, M. A. Mayes, L. Gu, C. W. Schadt, Representation of dormant and active microbial dynamics for ecosystem modeling, PloS one 9 (2) (2014) e89252. doi:http://dx.doi.org/10.1371/journal.pone.0089252.

[44] A. Konopka, Theoretical analysis of the starvation response under substrate pulses, Microbial Ecology 38 (4) (1999) 321-329. doi:http://dx.doi.org/10.1007/s002489900178.

[45] S. Kemmitt, C. V. Lanyon, I. Waite, Q. Wen, T. Addiscott, N. Bird, A. O'donnell, P. Brookes, Mineralization of native soil organic matter is not regulated by the size, activity or composition of the soil microbial biomass - a new perspective, Soil Bioløgy and Biochemistry 40 (1) (2008) 61-73. doi:http://dx.doi.org/10.1016/j.soilbio.2007.06.021.

[46] S. Blagodatsky, O. Richter, Microbial growth in soil and nitrogen turnover: a theoretical model considering the activity state of microorganisms, Soil Biology and Biochemistry 30 (13) (1998) 1743-1755. doi:http://dx.doi.org/10.1016/S0038-0717(98)00028-5.

[47] J. Ingwersen, C. Poll, T. Streck, E. Kandeler, Micro-scale modelling of carbon turnover driven by microbial succession at a biogeochemical interface, Soil Biology and Biochemistry 40 (4) (2008) 864-878. doi:http://dx.doi.org/10.1016/j.soilbio.2007.10.018.

[48] FAO, World reference base for soil resources: 2006: a framework for international classification, correlation and communication, FAO, 2006.

[49] S. Houot, D. Clergeot, J. Michelin, C. Francou, S. Bourgeois, G. Caria, H. Ciesielski, Agronomic value and environmental impacts of urban composts used in agriculture, Microbiology of Composting (2002) 457-472.

[50] N. Elyeznasni, F. Sellami, V. Pot, P. Benoit, L. VieubléGonod, I. Young, S. Peth, Exploration of soil micromorphology to identify coarse-sized om assemblages in $\mathrm{x}$-ray ct images 
of undisturbed cultivated soil cores, Geoderma 179 (2012) 38-45. doi:http://dx.doi.org/10.1016/j.geoderma.2012.02.023.

[51] R. Luxmoore, Micro-, meso- and macroporosity of soil, Soil Science Society of America Journal 45 (1981) 671-672.

[52] F. A. L. Dullien, Pore structure, in: Porous Media, Elsevier, 1992, pp. 5-115. doi:http://dx.doi.org/10.1016/b978-0-12-223651-8.50007-9.

[53] H.-J. Vogel, Morphological determination of pore connectivity as a function of pore size using serial sections, European Journal of Soil Science 48 (3) (1997) 365-377. doi:http://dx.doi.org/10/1111/j.13652389.1997.tb00203.x.

[54] J. Ohser, F. Mücklich, Statistical Analysis of Microstructures in Material Science, Wiley New York, 2000.

[55] H.-J. Vogel, W. Schlüter, Quantification of soil structure based on minkowski functions, Computers and Geosciences 36 (2010) 1236-1245. doi:http://dx.doi.org/10.1016/j.cageo.2010.03.007.

[56] M. B. Clennell, Tortuosity: a guide through the maze, Geological Society, London, Special Publications 122 (1) (1997) 299-344. doi:10.1144/gsl.sp.1997.122.01.18.

[57] C. J. Gommes, A.-J. Bons, S. Blacher, J. H. Dunsmuir, A. H. Tsou, Practical methods for measuring the tortuosity of porous materials from binary or gray-tone tomographic reconstructions, AIChE J. 55 (8) (2009) 2000-2012. doi:http://dx.doi.org/10.1002/aic.11812.

[58] M. Pinheiro, P. Garnier, L. Fabrice Martin, A. Rapaport, J. Beguet, L. Vieublé-Gonod, Impact of distribution heterogeneity of microorganisms and 2,4-D on biodegradation processes in soil : experiment and modelling, in: Conference on Pesticide Behaviour in Soils, Water and Air, University of York, 2013, p. 2.

[59] A. Genty, V. Pot, Numerical calculation of effective diffusion in unsaturated porous media by the TRT lattice Boltzmann method, Transport in Porous Media 105 (2014) 391-410. doi:http://dx.doi.org/10.1007/s11242-014-0374-8. 
[60] E. Guyon, J.-P. Hulin, P. L., Hydrodynamique physique, Savoirs Actuels Inter Editions et Editions du CNRS, 1991.

[61] T. Pintelon, C. Picioreanu, M. van Loosdrecht, M. Johns, The effet of biofilm permeability on bio-clogging of porous media, Biotechnology and Bioengineering 109 (2012) 1031-1042. doi:http://dx.doi.org/10.1002/bit.24381.

[62] N. Nunan, K. Wu, I. Young, J. Crawford, K. Ritz, Spatial distribution of bacterial communities and their relationships with the microarchitecture of soil, FEMS Microbiology Ecology 44 (2) (2003) 203-215. doi:http://dx.doi.org/10.1016/S0168-6496(03)00027-8

[63] G. Grundmann, A. Dechesne, F. Bartoli, J. Flandrois, J. Chasse, R. Kizungu, Spatial modeling of nitrifier microhabitats in soil, Soil Science Society of America Journal 65 (6) (2001) 1709-1716. doi:http://dx.doi.org/10.1111/j.1574-6941.2000.tb00754.x.

[64] G. Grundmann, D. Debouzie, Geostatistical analysis of the distribution of nh4 + and no2-oxidizing bacteria and serotypes at the millimeter scale along a soil transect, FEMS Microbiology Ecology 34 (1) (2000) 57-62. doi:http://dx.doi.org/10.1111/j.1574-6941.2000.tb00754.x.

[65] C. Nguyen, A. Guckert, Short-term utilisation of 14C-[U]glucose by soil microorganisms in relation to carbon availability, Soil Biology and Biochemistry 33 (1) (2001) 53 - 60. doi:http://dx.doi.org/10.1016/S00380717(00)00114-0.

[66] H. Van de Werf, W. Verstraete, Estimation of active soil microbial biomass by mathematical analysis of respiration curves: relation to conventional estimation of total biomass, Soil Biology and Biochemistry 19 (3) (1987) 267-271. doi:http://dx.doi.org/10.1016/00380717(87)90008-3.

[67] J. Stenström, K. Svensson, M. Johansson, Reversible transition between active and dormant microbial states in soil, FEMS Microbiology Ecology 36 (2-3) (2001) 93-104. doi:http://dx.doi.org/10.1016/S01686496(01)00122-2. 
[68] J. T. Lennon, S. E. Jones, Microbial seed banks: the ecological and evolutionary implications of dormancy, Nature Reviews Microbiology 9 (2) (2011) 119-130. doi:http://dx.doi.org/10.1038/nrmicro2504.

[69] GRC, Handbook of Chemistry and Physics, 66th Edition, GRC Press, Boca Raton, FL, 1986.

[70] A. Saltelli, K. Chan, E. M. Scott, et al., Sensitivity analysis, Vol. 134, Wiley New York, 2000.

[71] M. Lamboni, D. Makowski, S. Lehuger, B. Gabrielle, H. Monod, Multivariate global sensitivity analysis for dynamic crop models, Field Crops Research 113 (3) (2009) 312-320. doi:http://dx.doi.org/10.1016/j.fcr.2009.06.007.

[72] D. Wallach, D. Makowski, J. W. Jones, F. Brum, Working with Dynamic Crop Models: Methods, Tools and Examples for Agriculture and Environment, Academic Press, 2013, Ch. 5: Uncertainty and Sensitivity Analysis, pp. 161-204. doi:http://dx.doi.org/10.1016/b978-0-12-3970084.00005-8.

[73] R Core Team, R: A Language and Environment for Statistical Computing, R Foundation for Statistical Computing, Vienna, Austria (2014).

URL http://www.R-project.org/

[74] S. Reischke, J. Rousk, E. Bååth, The effects of glucose loading rates on bacterial and fungal growth in soil, Soil Biology and Biochemistry 70 (2014) 88-95. doi:http://dx.doi.org/10.1016/j.soilbio.2013.12.011.

[75] A. Don, C.Rödenbeck, G. Gleixner, Unexpected control of soil carbon turnover by soil carbon concentration, Environmental Chemistry Letters 11 (4) (2013) 407-413. doi:http://dx.doi.org/10.1007/s10311-013-0433-

[76] P. Schjonning, I. K. Thomsen, S. r. O. Petersen, K. Kristensen, B. T. Christensen, Relating soil microbial activity to water content and tillageinduced differences in soil structure, Geoderma 163 (3-4) (2011) 256-264. doi:http://dx.doi.org/10.1016/j.geoderma.2011.04.022. 
[77] H. J. Kim, J. Q. Boedicker, J. W. Choi, R. F. Ismagilov, Defined spatial structure stabilizes a synthetic multispecies bacterial community, Proceedings of the National Academy of Sciences 105 (47) (2008) 18188 18193. doi:http://dx.doi.org/10.1073/pnas.0807935105.

[78] C. Chenu, J. Hassink, J. Bloem, Short-term changes in the spatial distribution of microorganisms in soil aggregates as affected by glucose addition, Biology and Fertility of Soils 34 (5) (2001) 349-356. doi: http://dx.doi.org/10.1007/s003740100419.

[79] L. S. Ruamps, N. Nunan, C. Chenu, Microbial biogeography at the soil pore scale, Soil Biology and Biochemistry 43 (2) (2011) 280-286. doi:http://dx.doi.org/10.1016/j.soilbio.2010.10.010.

[80] L. Shaw, Y. Beaton, S. Sousa, L. Glover, K. Killham, A. Meharg, Mineralisation of 2, 4-dichlorophenol and glucose placed into the same or different hydrological domains as a bacterial inoculant, Soil Biology and Biochemistry 34 (4) (2002) 531-539. doi:http://dx.doi.org/10.1016/S0038-0717(01)00212-7.

[81] L. S. Ruamps, N. Nunan, V Pouteau, J. Leloup, X. Raynaud, V. Roy, C. Chenu, Regulation of soil organic C mineralisation at the pore scale, FEMS Microbiology Ecology 86 (1, SI) (2013) 26-35. doi:http://dx.doi.org/10.1111/1574-6941.12078. 